\title{
Effect of steel fibers on static and blast response of high strength concrete
}

\author{
B. Luccioni ${ }^{\mathrm{a}, *}$, F. Isla ${ }^{\mathrm{b}}$, R. Codina ${ }^{\mathrm{c}}$, D. Ambrosini ${ }^{\mathrm{d}}$, R. Zerbino ${ }^{\mathrm{e}}$, G. Giaccio $^{\mathrm{f}}$, M.C. Torrijos $^{\mathrm{e}}$ \\ ${ }^{a}$ Researcher CONICET, Structures Institute, National University of Tucumán, Av. Independencia 1800, 4000 S.M. de Tucumán, Argentina \\ ${ }^{\mathrm{b}}$ Post Doctoral CONICET fellow. Structures Institute, National University of Tucumán, Argentina \\ c Post Doctoral CONICET fellow, Engineering Faculty, National University of Cuyo, Argentina \\ ${ }^{\mathrm{d}}$ Researcher CONICET, Engineering Faculty, National University of Cuyo, Argentina \\ e Researcher CONICET, LEMIT, Engineering Faculty, National University of La Plata, Argentina \\ ${ }^{\mathrm{f}}$ Researcher CIC, LEMIT, Engineering Faculty, National University of La Plata, Argentina
}

\section{A R T I C L E I N F O}

\section{Article History:}

Received 3 March 2016

Revised 26 April 2017

Accepted 30 April 2017

Available online 1 May 2017

\section{Keywords:}

High strength concrete

Steel fibers

Toughness

Blast response

\begin{abstract}
A B S T R A C T
The advantages of High Strength Fiber Reinforced Concrete (HSFRC) in static behavior highlighted by many researchers suggest it is a promising material to withstand dynamic loads. However, available experimental results regarding blast performance of HSFRC structural elements are still limited. The results of exploratory series of tests using a high strength concrete, over $100 \mathrm{MPa}$ compressive strength, reinforced with long hooked-end steel fibers are presented in this paper. The results of static characterization tests performed on prisms and slabs and the results of blast tests on slabs are presented and analyzed. The improvements found in static flexure response with different fibers contents are compared with those found under blast loads. The effects of fibers controlling cracking, scabbing and spalling under close-in explosions are also addressed.
\end{abstract} (C) 2017 Elsevier Ltd. All rights reserved.

\section{Introduction}

The addition of ductile and high strength fibers allows reducing the brittle nature of concrete and leads to a significant increase of ductility and energy absorption capacity $[1,2]$. Fiber Reinforced Concrete (FRC) [1], High Strength Fiber Reinforced Concrete (HSFRC) [3] and Ultra High Performance Fiber Reinforced Concrete (UHPFRC) [4] present great advantages for withstanding extreme actions when compared with conventional concrete and constitute promissory materials for protective structures that help saving lives and improving the strength and durability of buildings and infrastructure under extreme loads.

Fibers intercept the cracks delaying their propagation. The improvements are mainly related to the load transfer process from the matrix to the fibers through the cracks. For a certain concrete matrix the type and content of fibers are the most important parameters defining tension behavior of FRC [5-7], HSFRC $[1,8,9]$ and UHPFRC [10-14]. There are several types of fibers with different geometries and materials. Deformation or end anchorage like hooked ends can greatly increase the fibers pullout strength and the composite toughness $[15,16]$.

\footnotetext{
Corresponding author.

E-mail address: bluccioni@herrera.unt.edu.ar (B. Luccioni).
}

The advantages of FRC, HSFRC and UHPFRC in static behavior highlighted by many researchers suggest them as promising materials to withstand dynamic loads. Current understanding of the behavior of HSFRC [17] and UHPFRC $[4,12,13,18]$ under high strain rate loads is still very limited and some of the results reported by different authors are contradictory [19]. On the other side, although research regarding the effect of blast loads on FRC elements has been published during the last decades [20-26], available experimental results regarding blast performance of HSFRC [27-30] and UHPFRC [31-38] structural elements are still limited.

Blast tests performed on FRC panels showed that they behave better than normal concrete (NC) panels [20] or reinforced concrete (RC) panels [25]. They are less likely to fracture [20,21] and fibers help controlling spalling $[21,22,24]$. The volume of the spall failure decreases with the increase of fiber content [22]. It was also proved that for high fiber contents the increase of fiber volume does not significantly improve its performance [20]. A slight reduction of crater on the top face with the addition of fibers was observed under contact explosions [22].

Zhou et al. [28] reported results of blast tests on RC and HSFRC (steel fibers) panels and they observed that in all cases the damage area was smaller for the HSFRC slabs than for the RC slabs. Schenker et al. [29] tested NC and HSFRC slabs exposed to air blast and they showed that the damage, accelerations and displacements were lower for HSFRC specimens than for NC specimens. It was also 
proved that the addition of fibers to HCS improves its behavior as blast protection material [30].

The blast behavior of panel components made of UHPFRC, has been reported in several papers [32]. The UHPFRC panels showed higher strength [38] and ductility [37], lower permanent deformation and greater ability to absorb energy without fragmentation than conventional concrete panels $[33,34,36,37]$. Specimens are more likely to preserve integrity $[35,36]$. It was also proved that its resistance is increased with the increase of fiber volume [31] and that both straight and hooked end steel fibers have similar effects improving blast strength [31].

There is not much experimental information about the blast behavior of HSFRC slabs reported in the literature. Moreover, results of HSFRC under contact explosions are very scarce. More tests are required for a better understanding of HSFRC performance under blast loads and to assess the effect of different types and contents of fibers on blast response and blast damage under different blast scenarios.

The experimental results corresponding to an exploratory series of tests using HSFRC with different contents of hooked-end steel fibers are presented in this paper. The final objective of the research is the development of design and application criteria of HSFRC for a better understanding and use of these materials for the construction of structures exposed to extreme actions and, particularly, protective structures. The tests were specially designed to analyze the effect of long hooked end steel fibers on blast performance of HSFRC. The improvements under blast loads due to fiber addition are analyzed and compared with those obtained in static flexure. The results are also compared with those obtained by other authors for FRC, HSFRC and UHPFRC with different types of fibers.

The main contribution of the paper is a complete set of experimental results including HSC and HSFRC with two fibers contents ( $1 \%$ and $0.5 \%$ ) under static and blast loads corresponding to different scaled distances and contact explosions. Particularly, blast results involving cratering, spalling and flexure damage for HSFRC elements with different contents of long hooked end steel fibers contribute to complete the few results available in the literature.

Moreover, the conclusions of the paper can help understanding the role of long hooked end steel fibers on HSFRC blast behavior and optimizing the fiber content to reduce costs while preserving high performance.

Additionally, the experimental results presented and discussed in this paper can be useful data to calibrate and to validate numerical static models for HSFRC [39] since the behavior of the components and the composite for different fibers contents are reported. The results from blast tests represent macro-structural HSFRC behavior at high strain rates and can be used to validate HSFRC dynamic composite models for HSFRC.

\section{Experimental program}

\subsection{Materials and mixtures}

Three types of concrete were studied and compared: a HSC (P) and two HSFRC (F40, F80). All concretes were prepared using the same base self-compacting matrix. Concrete mixture proportions are presented in Table 1 . Considering that strength levels over $100 \mathrm{MPa}$ were expected, hooked-end high carbon steel fibers of $60 \mathrm{~mm}$ length and $0.7 \mathrm{~mm}$ diameter with a nominal tensile strength of 2300 MPa were used for HSFRC. F40 and F80 incorporate $40 \mathrm{~kg} / \mathrm{m}^{3}$ of fibers $\left(0.5 \%\right.$ volume content) and $80 \mathrm{~kg} / \mathrm{m}^{3}$ of fibers ( $1 \%$ volume content) respectively. For the selected fiber type and size of coarse aggregate used, $40 \mathrm{~kg} / \mathrm{m}^{3}$ is a medium to high content while $80 \mathrm{~kg}$ / $\mathrm{m}^{3}$ represents a very high fiber content.

Concrete $\mathrm{P}$, without fibers, had high fluidity and filling capacity achieving a slump flow diameter of $550 \mathrm{~mm}$ and a $\mathrm{T}_{50}$ equal to $6.2 \mathrm{~s}$.
Table 1

Concrete $(\mathrm{P})$ mixture proportions and fresh properties.

\begin{tabular}{ll}
\hline Material & Content \\
\hline Portland cement $\left[\mathrm{kg} / \mathrm{m}^{3}\right]$ & 730 \\
Silica fume $\left[\mathrm{kg} / \mathrm{m}^{3}\right]$ & 73 \\
Calcareous filler $\left[\mathrm{kg} / \mathrm{m}^{3}\right]$ & 48 \\
Natural siliceous sand $\left[\mathrm{kg} / \mathrm{m}^{3}\right]$ & 490 \\
Granitic crushed stone $\left(12 \mathrm{~mm}^{3}\right.$ maximum size $)\left[\mathrm{kg} / \mathrm{m}^{3}\right]$ & 860 \\
Set retarding plasticizer $\left[\mathrm{kg} / \mathrm{m}^{3}\right]$ & 1.0 \\
High range water reducer $\left[\mathrm{kg} / \mathrm{m}^{3}\right]$ & 8.9 \\
Water/cement+ silica fume ratio & 0.24 \\
Fresh properties & \\
Slump flow diameter $[\mathrm{mm}]$ & 550 \\
$\mathrm{~T}_{50}[\mathrm{~s}]$ & 6.2 \\
Air content [\%] & 3.8 \\
\hline
\end{tabular}

As expected, slump flow diameter was reduced $(490 \pm 20 \mathrm{~mm})$ with the addition of fibers but the conditions for good filling and compaction were preserved. In all cases the air content measured on fresh concrete according to ASTM C231/C231M - 14 [40] was $3.8 \pm 0.2 \%$.

To evaluate the compression strength, $100 \mathrm{~mm} \times 200 \mathrm{~mm}$ cylinders and $70 \mathrm{~mm}$ side cubes were cast. Taking into account the strength of the matrix, the cylinders were capped with a high strength cement mortar. The cylinders were also used to determine the static elastic modulus according to ASTM C469/ C469M - 14 Standard [41].

Four square slabs of $550 \mathrm{~mm}$ side and $50 \mathrm{~mm}$ height were molded with each concrete; three of them for testing under blast loads and the remaining to evaluate the static flexure behavior. Three prisms of $430 \mathrm{~mm} \times 50 \mathrm{~mm} \times 105 \mathrm{~mm}$ were cast for bending characterization of concrete $\mathrm{P}$ and four prisms were molded in the case of F40 and F80. All the specimens were cured 28 days in moist room and then stored at the laboratory environment during four months until the characterization and blast tests were performed.

In addition, with the aim of obtaining useful information for the numerical analysis, 40 pull-out specimens consisting of $40 \mathrm{~mm} \times 40 \mathrm{~mm} \times 60 \mathrm{~mm}$ concrete $\mathrm{P}$ prisms with half a fiber immersed in them were cast and some fibers were tested in tension to verify their strength.

The aspect of fresh concrete and the concrete pouring are shown in Fig. 1. Due to the self-compacting nature of the concrete matrix, neither vibration nor any additional action was required to guarantee a proper compaction of the specimens.

\subsection{Tests description and results}

\subsubsection{Static tests for concrete characterization}

Compression tests were performed on cylinders and on small cubes for concrete characterization: The cube has the advantage of avoiding any capping defect that could affect the measured strength but a possible disadvantage could be the lack of compaction in the case of the HSFRC used in the present tests.

The compressive tests results are presented in Table 2. The average result of four tests and the standard deviation are informed in each case.

As it is well known, bending tests are usually adopted for FRC mechanical characterization. Nowadays the fib Model Code [42] adopts the EN 14651 standard [43] for that purpose, defining FRC classes that are based on the residual strengths. In this research the bending tests were performed on small beams (with thickness comparable to the slabs) following the guidelines of EN 14651 standard. A notch of approximately $19 \mathrm{~mm}$ was sawn in the beams central section. The beams were tested under three points loading with a free span of $350 \mathrm{~mm}$. A loading rate of $0.08 \mathrm{~mm} / \mathrm{min}$ was applied for the case of plain concrete, while for concretes F40 and F80, this loading rate was applied until the vertical displacement reached $1 \mathrm{~mm}$ and 


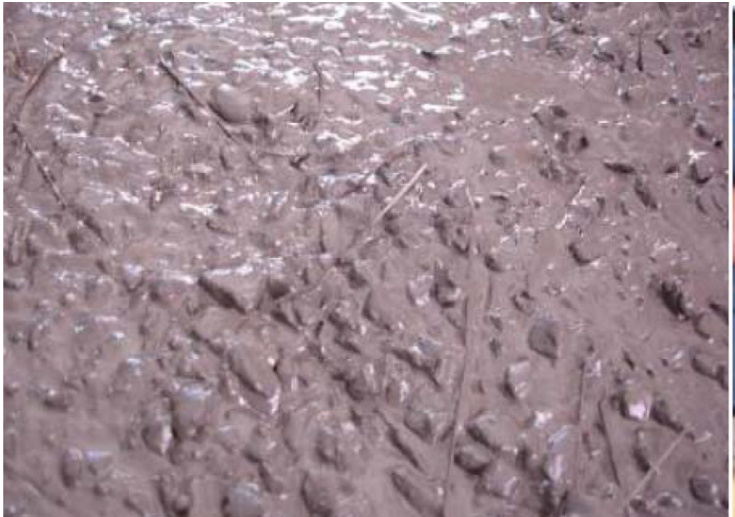

(a)

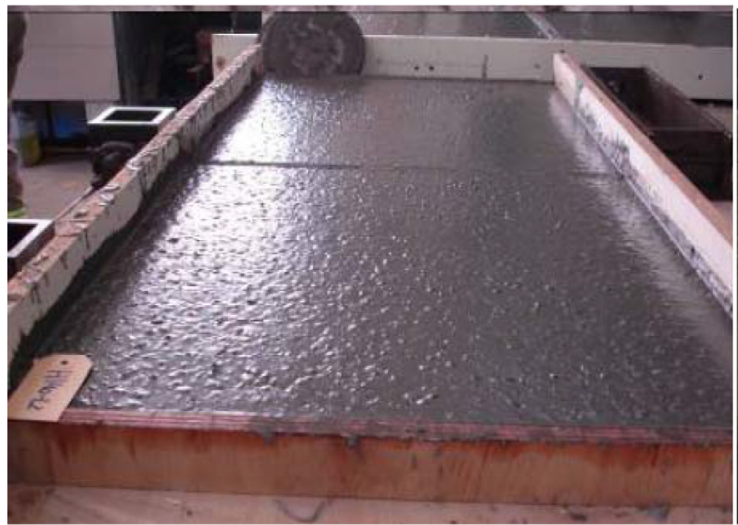

(c)

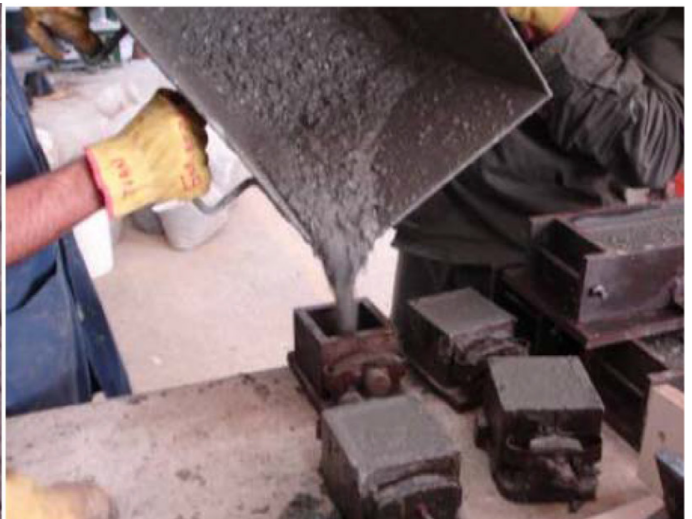

(b)

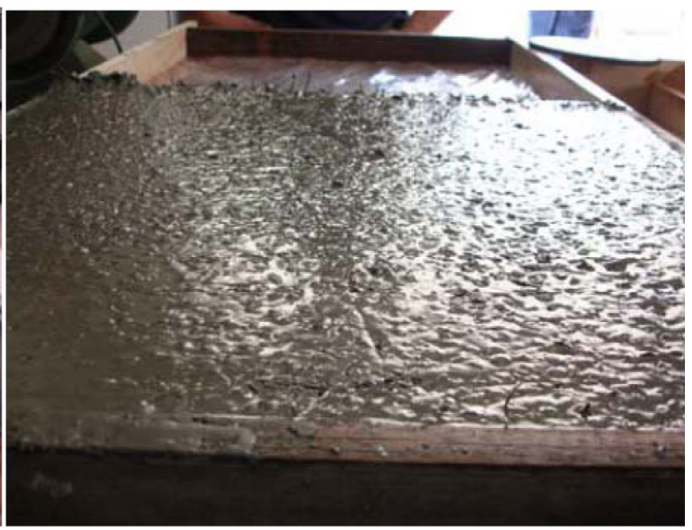

(d)

Fig. 1. Specimens preparation: (a) Concrete aspect (b) Filling of concrete cubes (c) HSC slab and (d) HSFRC slab.

Table 2

Results from compression tests.

\begin{tabular}{llll}
\hline Concrete & P & F40 & F80 \\
\hline Compressive strength on cubes [MPa] & $121(9)$ & $114(5)$ & $113(5)$ \\
Compressive strength on cylinders [MPa] & $114(5)$ & $109(4)$ & $109(3)$ \\
Modulus of elasticity [GPa] & $40(1)$ & $39(2)$ & $41(1)$ \\
\hline
\end{tabular}

(): standard deviation

then, it was increased to $0.5 \mathrm{~mm} / \mathrm{min}$ up to the end of the tests. The crack mouth opening displacement (CMOD) and the vertical displacements of the beam center at both sides were registered. The
stress-CMOD curves of bending tests for the three mixtures are presented in Fig. 2. The first peak (maximum stress up to $C M O D=0.05$ $\mathrm{mm})\left(f_{\mathrm{L}}\right)$, the maximum stress $\left(f_{\max }\right)$ and two residual stresses $\left(f_{\mathrm{R} 1}\right.$, $f_{\mathrm{R} 3}$ ) corresponding to $\mathrm{CMOD}_{1}=0.5 \mathrm{~mm}$ and $\mathrm{CMOD}_{3}=2.5 \mathrm{~mm}$ [43] were calculated as it is indicated in [44] and presented in Table 3.

Fig. 3 shows a view of some prisms after testing. It must be noted that in F80, even in presence of the notch that normally defines the fracture plane, multiple cracks have been developed, making evident the significant crack control resulting from high fiber content. After the tests, specimens were separated in two parts and the fibers crossing the central section were counted, see Fig. 3b. The resulting number and density of fibers in the crack section are also presented
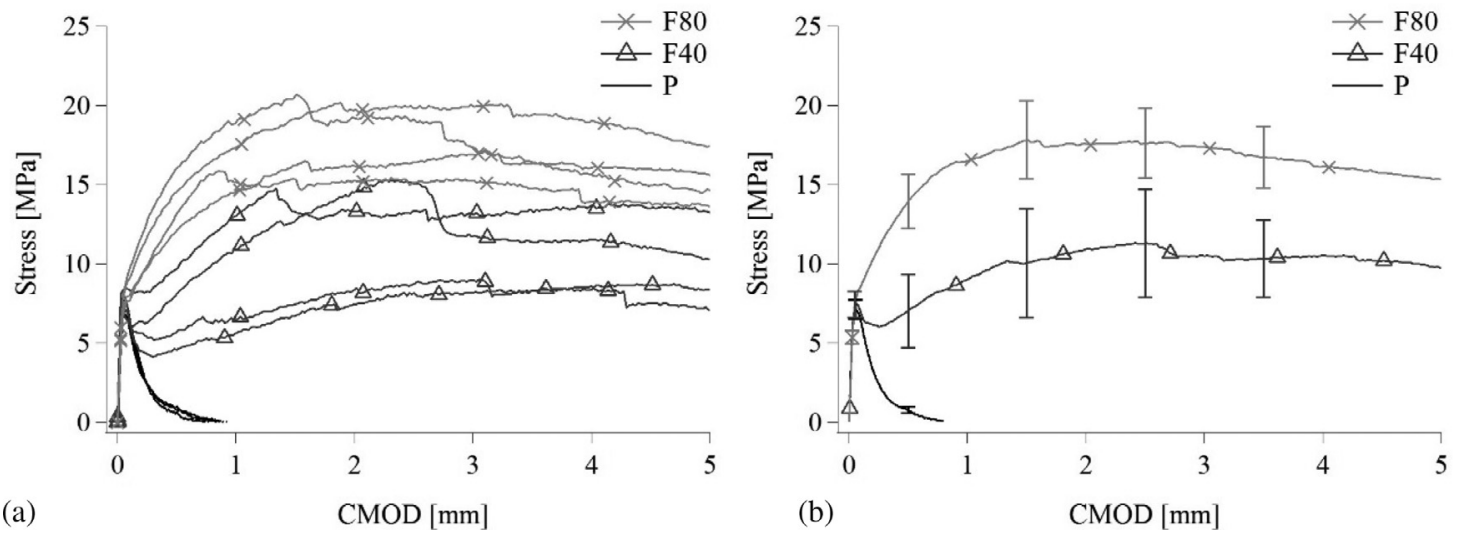

Fig. 2. Bending tests: (a) Stress-CMOD curves and (b) Average Stress-CMOD curves and standard deviation. 
Table 3

Individual bending tests results.

\begin{tabular}{lllllll}
\hline Prisms & $\begin{array}{l}f_{\mathrm{L}} \\
{[\mathrm{MPa}]}\end{array}$ & $\begin{array}{l}f_{\max } \\
{[\mathrm{MPa}]}\end{array}$ & $\begin{array}{l}f_{\mathrm{R} 1} \\
{[\mathrm{MPa}]}\end{array}$ & $\begin{array}{l}f_{\mathrm{R} 3} \\
{[\mathrm{MPa}]}\end{array}$ & Number of fibers & $\begin{array}{l}\text { Density } \\
{\left[\text { Fibers } / \mathrm{mm}^{2}\right]}\end{array}$ \\
\hline P-1 & 7.9 & 7.9 & - & - & - & - \\
P-2 & 6.8 & 6.8 & - & - & - & - \\
P-3 & 7.0 & 7.0 & - & - & - & - \\
Average & 7.3 & 7.3 & - & - & - & - \\
F40-1 & 8.2 & 9.0 & 5.6 & 8.7 & 27 & 0.0063 \\
F40-2 & 6.9 & 8.8 & 4.6 & 8.1 & 31 & 0.0064 \\
F40-3 & 6.8 & 15.4 & 8.1 & 15.0 & 52 & 0.0110 \\
F40-4 & 8.5 & 14.9 & 9.9 & 13.3 & 65 & 0.0139 \\
Average & 7.6 & 12.0 & 7.0 & 11.3 & & 0.0208 \\
F80-1 & 7.3 & 17.1 & 12.0 & 16.4 & 108 & 0.0173 \\
F80-2 & 7.1 & 16.0 & 13.1 & 15.1 & 84 & 0.0179 \\
F80-3 & 7.9 & 20.2 & 14.7 & 19.8 & 83 & 0.0198 \\
F80-4 & 8.0 & 20.8 & 15.9 & 19.2 & 96 & \\
Average & 7.6 & 18.5 & 13.9 & 17.6 & & \\
\hline
\end{tabular}

in Table 3. It was observed that most of the fibers were oriented in axial direction, that no fibers were cut and that some of the fibers hooks were straightened.

One slab of each mixture was tested under flexure following the general guidelines of the BS EN 14488-5 standard [45]. The slabs were supported on a $570 \mathrm{~mm}$ side metallic frame leaving a free span of $470 \mathrm{~mm}$. Load was applied with a thick square plate of $100 \mathrm{~mm}$ side located in the center of the slabs. The loading rate was initially equal to $1 \mathrm{~mm} / \mathrm{min}$ and it was increased to $3 \mathrm{~mm} / \mathrm{min}$ after the displacement registered by an LVDT located on the center of the slab bottom face achieved $4 \mathrm{~mm}$. A picture of the test setup is shown in Fig. 4(a), while the load-displacement curves registered for the three concretes are presented in Fig. 4(b). The load corresponding to the first peak or first crack $\left(\mathrm{P}_{\mathrm{L}}\right)$, the maximum load $\left(\mathrm{P}_{\max }\right)$, and the energy absorption capacity up to a deflection of $25 \mathrm{~mm}$ are presented in Table 4. It must be noted that these slabs are only $50 \mathrm{~mm}$ thick, while the standard test refers to $100 \mathrm{~mm}$ thick slabs. Fig. 5 shows pictures of the three slabs after testing. Finally, the slabs were sawn in order to evaluate the fiber density in different directions; the results are also included in Table 4. As expected, the fibers were mostly oriented in horizontal planes. In this case the length of the fibers and the slab thickness make the 2D distribution of the reinforcement more marked. The distribution of fibers in slabs could be clearly identified after blast tests and will be shown in Section 3.2.

Complementary to concrete tests, the fiber tensile strength as well as their pull-out behavior were studied. Five fibers were tested in direct tension; the average value of the tensile strength was $2320 \mathrm{MPa}$ with a standard deviation of $65 \mathrm{MPa}$. Pull-out tests were performed on 40 specimens. A photograph of the specimen is shown in Fig. 6(a), while the resulting load-displacement average curve, with the standard deviation, is included in Fig. 6(b). The embedded length was half the fiber length $(30 \mathrm{~mm})$. The pull-out rate was varied in the range $1-500 \mathrm{~mm} / \mathrm{min}(0.017-8.33 \mathrm{~mm} / \mathrm{s})$. The resulting average load-displacement curves for the different velocities were almost coincident.

\subsubsection{Blast tests}

When a blast load is detonated close to a concrete slab it produces a shock wave that infringes on the slab surface and local failure can be observed. The slab surface facing the explosion is subjected to high triaxial compression stresses that may cause material local failure [46] characterized by a crater. Part of the energy is reflected and the other part is propagated through the slab thickness. When this wave reaches the rear surface, a new reflection of the compression wave occurs originating a tension rebound from the rear face that can cause concrete spalling and particle ejection at the rear face. Theoretical analysis on the spall damage is quite complex. If the explosive is detonated at a greater distance, it could cause flexure failure. If the stand-off distance is reduced a localized punching shear failure can take place before the slab can respond in flexural mode.

It can be expected that the improvements of HSC static strength and toughness due to the fiber incorporation will also help controlling front face cratering, rear face concrete spalling, flexural and punching shear damage produced by blast loads. With the aim of studying the effect of fibers addition on different types of damages, different explosive masses and standoff distances were used in blast tests. Three types of blast tests described in Table 5 were performed on slabs of concretes P, F40, and F80.
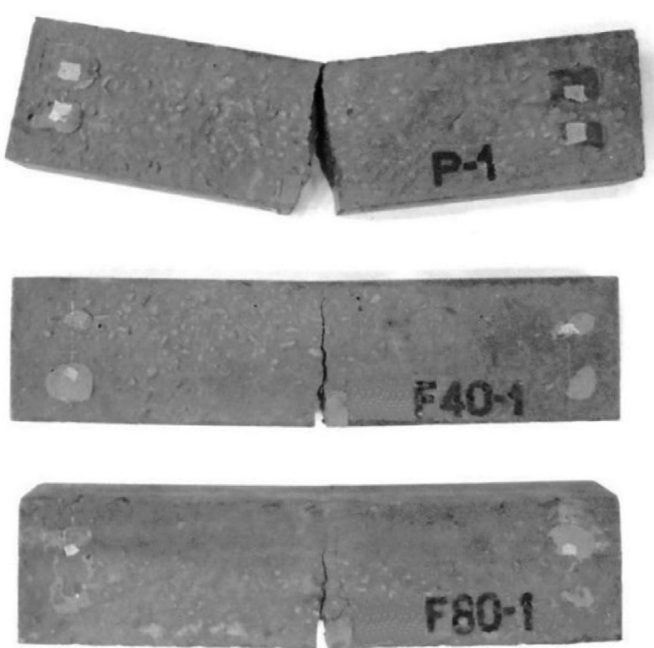

(a)
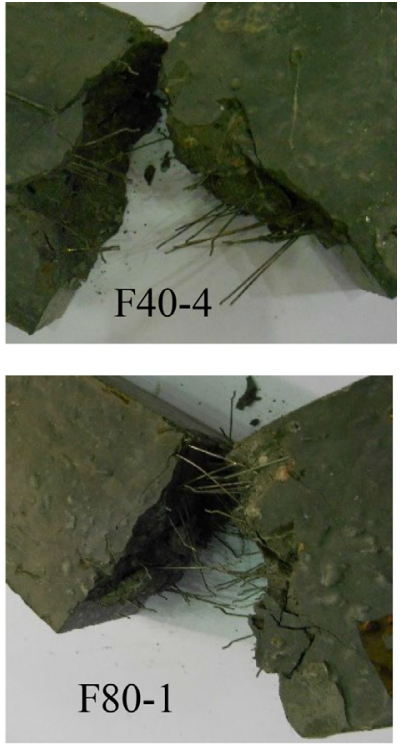

(b)

Fig. 3. Beams Tested. a) Beams after bending tests and b) Detail of fibers orientation at the fracture surfaces. 


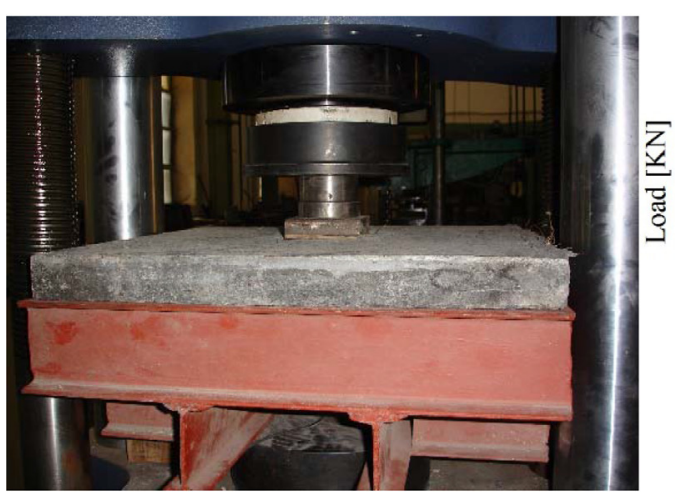

(a)

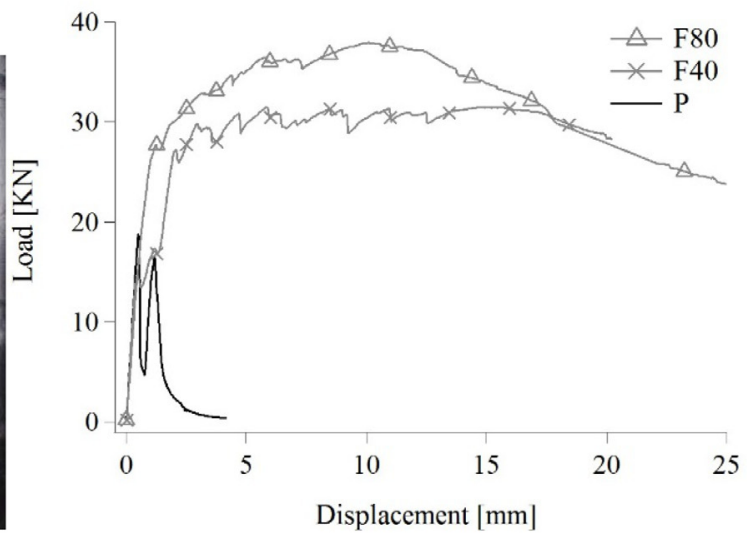

(b)

Fig. 4. Slabs bending tests: (a) Test setup and (b) Load-displacement curves.

Table 4

Slabs static tests results.

\begin{tabular}{lllllll}
\hline Slabs & $\mathrm{P}_{\mathrm{L}}$ & $\mathrm{P}_{\max }$ & Energy & Density & & \\
\cline { 6 - 7 } & {$[\mathrm{kN}]$} & {$[\mathrm{kN}]$} & {$[\mathrm{kJ}]$} & $\begin{array}{l}\text { plane } \perp x \\
{\left[\text { Fibers } / \mathrm{mm}^{2}\right]}\end{array}$ & $\begin{array}{l}\text { plane } \perp y \\
{\left[\text { Fibers } / \mathrm{mm}^{2}\right]}\end{array}$ & $\begin{array}{l}\text { Average } \\
{\left[\text { Fibers } / \mathrm{mm}^{2}\right]}\end{array}$ \\
\hline $\mathrm{P}$ & 18.4 & 18.4 & 0.02 & - & - & 0 \\
F40 & 14.3 & 30.9 & 0.68 & 0.0079 & 0.0090 & 0.0084 \\
F80 & 27.2 & 37.2 & 0.91 & 0.0180 & 0.0232 & 0.0206 \\
\hline
\end{tabular}

The slabs were supported on a highly reinforced steel frame leaving a free span of $460 \mathrm{~mm}$ as shown in Fig. 7. The frame has L shape plates at the corners to prevent the slabs going upwards due to the negative phase of the blast wave.
A gel-like explosive formed by a semi-plastic mass consisting of a gelatin nitroglycerine and nitrocellulose incorporating ammonium salts and additives was used for the blast tests. It has a nominal TNT equivalence of 0.65 in weight. In all cases, the explosive had cylindrical shape and the detonator was located in the center of the upper surface, see Fig. 7. In the case of explosions elevated above the slabs, the explosive was supported on an expanded polystyrene block as shown in Fig. 7(b).

The blast pressure time histories were recorded using pressure sensors in some previous tests specially developed to verify the explosive TNT equivalence and in most of the slabs tests. The pressure sensor was located at $1 \mathrm{~m}$ height from the ground surface. More details about the pressure measurement can be found in Codina et al. [47]. The main parameters of the reflected blast wave corresponding to two different masses of explosive are given in Table 6 where the distance from the explosive to the pressure sensor is also
$\mathrm{P}$

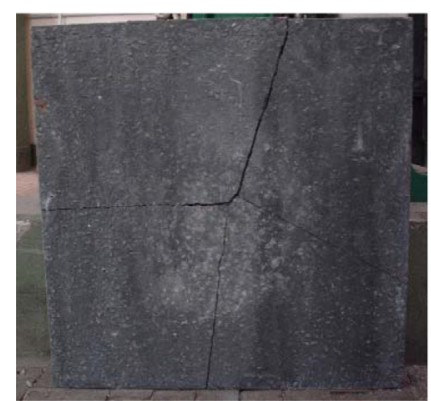

(a)

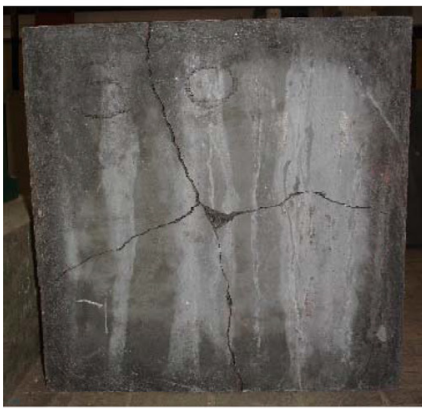

F40
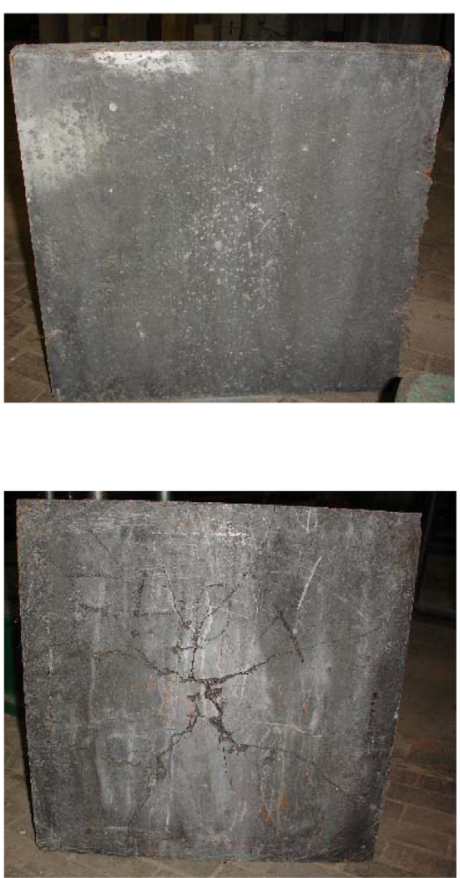

F80
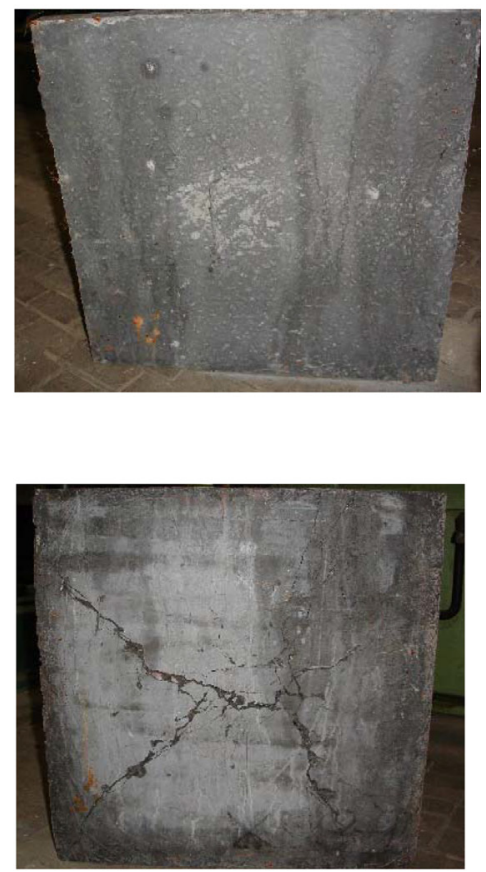

(b)

Fig. 5. Slabs damage after the static bending tests: (a) Top face and (b) Bottom face. 


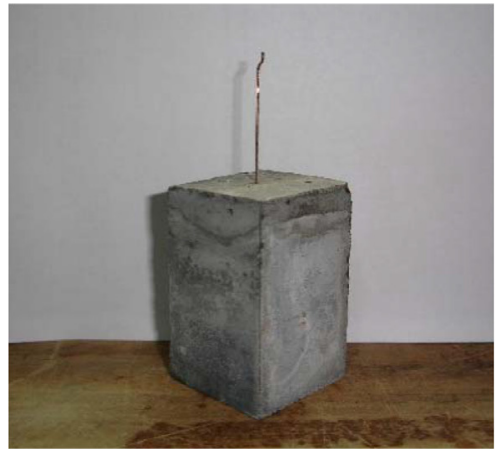

(a)

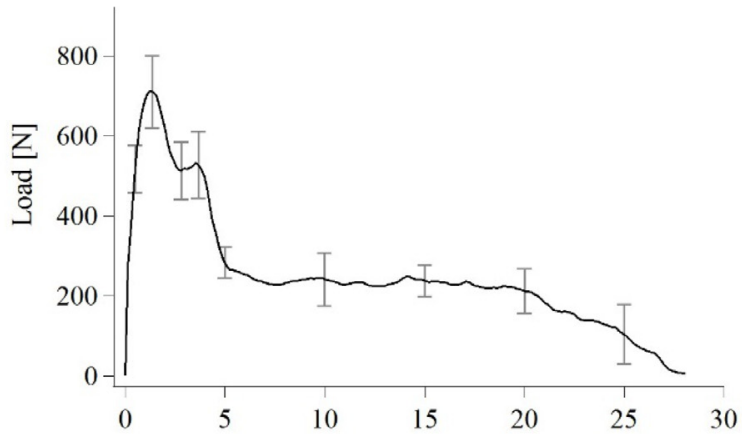

(b)

Fiber end displacement [mm]

Fig. 6. Pull-out tests: (a) Specimen tested and (b) Pull-out response (average and standard deviation).

Table 5

Blast tests description.

\begin{tabular}{|c|c|c|c|c|c|c|c|}
\hline \multirow[t]{2}{*}{$\begin{array}{l}\text { Blast test } \\
\text { Type }\end{array}$} & \multicolumn{3}{|c|}{$\begin{array}{l}\text { Concrete mixtures } \\
\text { (slab identification) }\end{array}$} & \multirow{2}{*}{$\begin{array}{l}\text { Explosive (Gel 65\%) } \\
\text { mass } \\
{[\mathrm{kg}]}\end{array}$} & \multirow{2}{*}{$\begin{array}{l}\text { TNT equivalent } \\
\text { mass } \\
{[\mathrm{kg}]}\end{array}$} & \multirow{2}{*}{$\begin{array}{l}\text { Explosive gravity center } \\
\text { height over slab } \\
{[\mathrm{m}]}\end{array}$} & \multirow{2}{*}{$\begin{array}{l}\text { Scaled } \\
\text { distance Z } \\
{\left[\mathrm{m} / \mathrm{kg}^{1 / 3}\right]}\end{array}$} \\
\hline & $\mathrm{P}$ & F40 & F80 & & & & \\
\hline I & $\mathrm{P} 1$ & F401 & F801 & 0.075 & 0.049 & 0.0175 & 0.05 \\
\hline II & $\mathrm{P} 2$ & F402 & F802 & 0.375 & 0.244 & 0.2425 & 0.39 \\
\hline III & P3 & F403 & F803 & 0.750 & 0.488 & 0.2725 & 0.35 \\
\hline
\end{tabular}

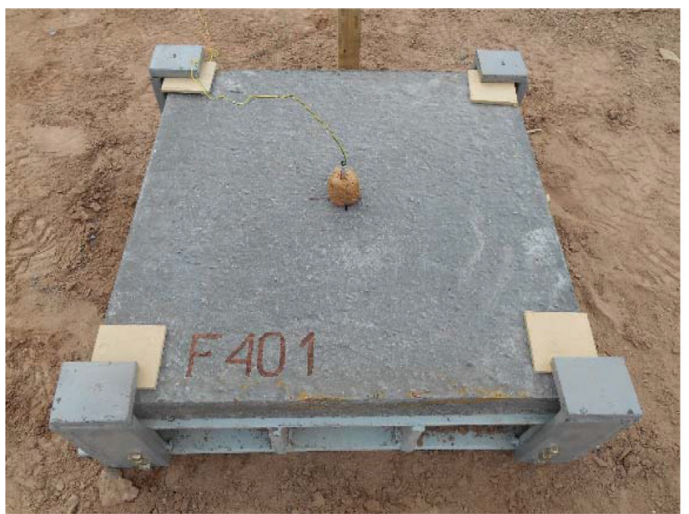

(a)

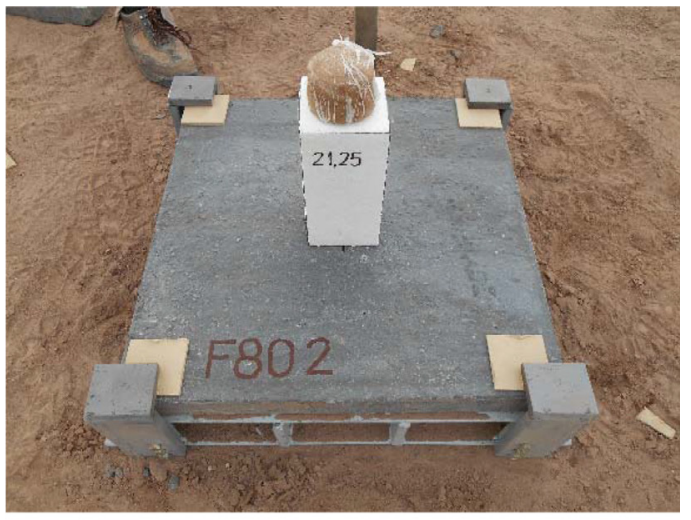

(b)

Fig. 7. Blast tests setup: (a) Contact explosion (Type I) and (b) Elevated explosion (Type II).

indicated. These two blast events that were in the range of the explosive masses detonated in slabs blast tests correspond to $1.5 \mathrm{~kg}$ of explosive located at $1 \mathrm{~m}$ from ground level and $0.375 \mathrm{~kg}$ of explosive elevated $0.2425 \mathrm{~m}$ above the concrete slab. According to the TNT equivalence given by the explosive provider, these amounts of explosive correspond to $0.975 \mathrm{~kg}$ and $0.244 \mathrm{~kg}$ of equivalent TNT respectively. In order to verify the TNT equivalence, these two explosions were numerically simulated using AUTODYN software [48].

In both cases, the explosion was first simulated in a very refined mesh ( mesh size $=1.5 \mathrm{~mm}$ ) from the detonation instant and then, before the pressure wave reached the borders of the model, the results were mapped on a bigger and coarser model (mesh size $=10 \mathrm{~mm}$ ) to simulate the propagation of the blast wave until it reaches the point corresponding to the pressure sensor.

An axial symmetric mesh and an Euler Gudunov processor were used for the first step of the numerical simulation. Taking into account that the reflected overpressure and impulse values depend on the shape of the explosive charge, in this first step the explosive was modeled with its actual cylindrical shape. The ideal gas equation of state was used for the air while Lee-Tarver equation of state was
Table 6

TNT equivalence validation.

\begin{tabular}{llll}
\hline Explosive mass [kg] & & 1.500 & 0.375 \\
TNT equivalent W [kg] & & 0.975 & 0.244 \\
Distance d [m] & & 15.0 & 18.0 \\
Scaled distance $Z=\mathrm{d} / \mathrm{W}^{1 / 3}\left[\mathrm{~m} / \mathrm{kg}^{1 / 3}\right]$ & & 15.13 & 28.82 \\
Peak positive reflected overpressure [kPa] & Exp & 17.3 & 7.5 \\
& Num & 18.1 & 7.5 \\
& UFC [49] & 18.1 & 7.6 \\
Peak negative reflected overpressure [kPa] & Exp & 3.3 & 2.0 \\
& Num & 4.2 & 2.0 \\
& UFC [49] & OOR* & OOR* \\
Duration positive phase [ms] & Exp & 4.9 & 3.3 \\
& Num & 4.9 & 3.4 \\
& UFC [49] & 5.3 & 3.8 \\
Duration negative phase [ms] & Exp & 9.6 & 6.4 \\
& Num & 9.6 & 5.8 \\
Maximum reflected impulse [Pa s] & UFC [49] & OOR* & OOR* \\
& Exp & 17.0 & 5.9 \\
& Num & 19.6 & 5.9 \\
& UFC [49] & 39.2 & 11.8 \\
\hline
\end{tabular}

"OOR: Out of range 
used to model both the detonation and expansion of TNT in conjunction with "Jones -Wilkins -Lee" (JWL EOS) for the unreacted explosive. In order to simulate a free field explosion, flow out of air was allowed in all the model borders. The detonation of the explosive was initiated on the top of the cylindrical explosive charge axis as in the tests.

The second numerical simulation was performed with an axial symmetric mesh of $40 \mathrm{~m}$ diameter and $10 \mathrm{~m}$ height and an Euler FCT processor. The explosive locations in the models were identical to those used in the tests. Flow out was allowed in all mesh borders except for the base representing the ground. In the case of the smaller explosion the concrete slab was simulated as a rigid object. Additionally, a rigid object with similar shape to the pressure sensors box was defined in order to accurately reproduce the effect of the sensor box on the blast wave.

The main blast wave parameters numerically obtained are also included in Table 6 together with values calculated according to UFC 3-340-02 [49] for hemispherical surface explosives. The slight differences found between numerical values obtained with the nominal TNT equivalence and experimental values confirm that the TNT equivalence of 0.65 is correct. The differences between the values calculated according to UFC-3-340-02 and experimental results can be attributed to the shape and position of the explosive load.
A general view of the damage pattern produced by the different blast tests (types I, II and III) on the three slabs of each concrete are presented in Fig. 8 (front face) and 9 (rear face). Table 7 summarizes the main observations regarding slabs damage characteristics after blast tests, the size of the craters and the cracks width measured on the front and the rear faces of each slab, the lateral side defects and the maximum residual deflection of the front face are indicated.

\section{Discussion}

\subsection{Characterization tests}

A concrete with very high compression strength (114 MPa) was obtained. The compression tests results presented in Table 2 show a slight decrease in strength with the addition of fibers (greater in the cubes) while the elasticity modulus remains almost constant. This effect was also found by the authors in previous tests with normal and high strength self-compacting concrete matrix and hooked end steel fibers [50,51] and by Buratti et al. [7] and Caggiano et al. [52] for FRC with the same type of steel fibers. In contrast, Nili et al [53] found increases from 12 to $19 \%$ due to the addition of 0.5 to $1 \%$ of long hooked end steel fibers to a normal strength matrix, depending on the constitution of the matrix. Song and Hwang [2] obtained
Test type

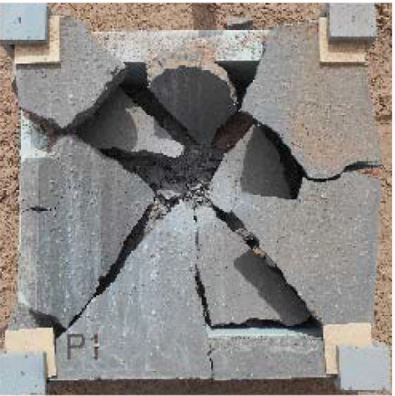

II

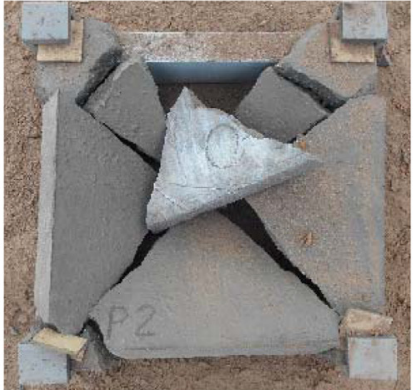

III

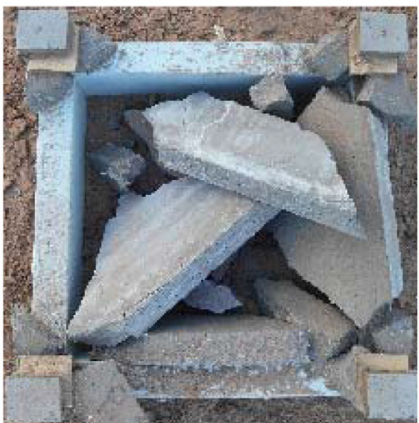

Concrete F40
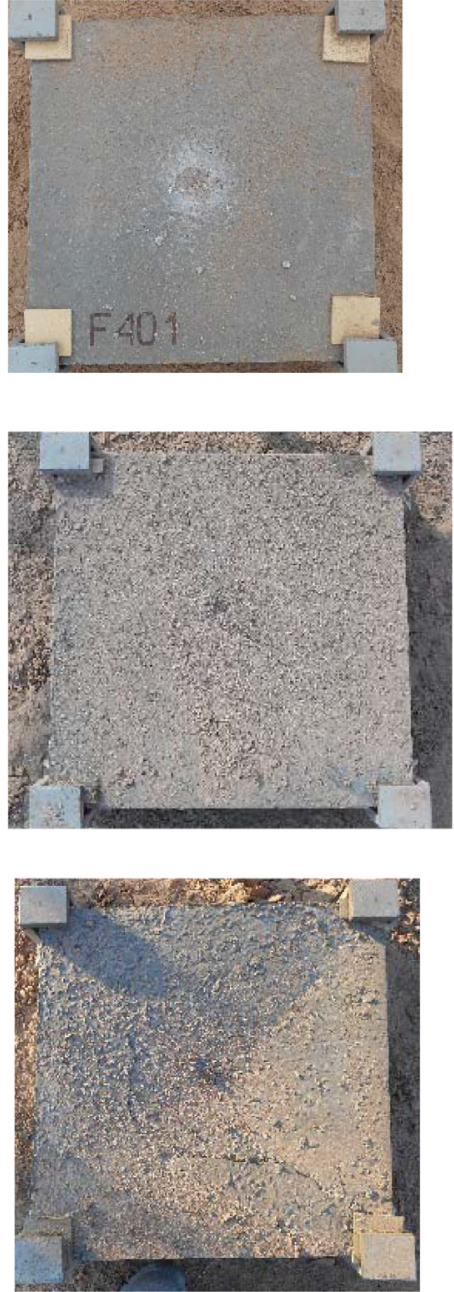

Fig. 8. Slabs front face after blast tests.
Concrete F80
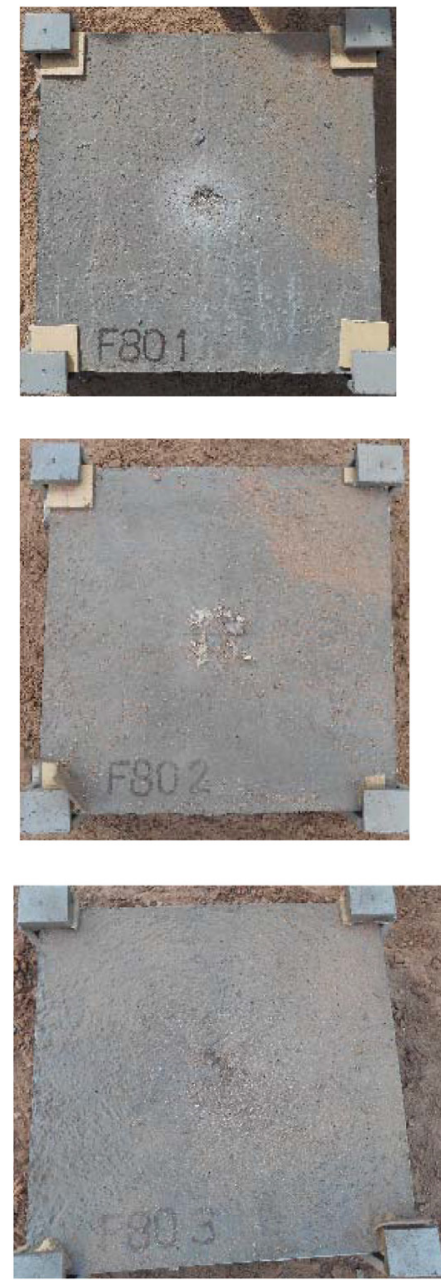
Test type

I

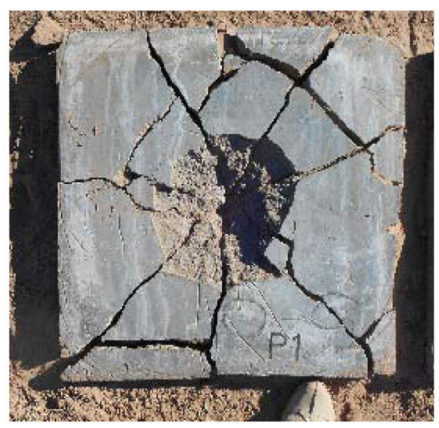

II

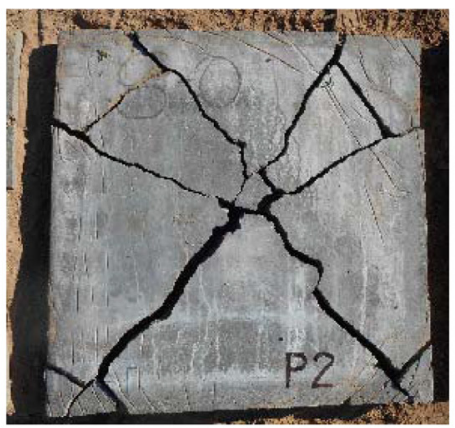

III

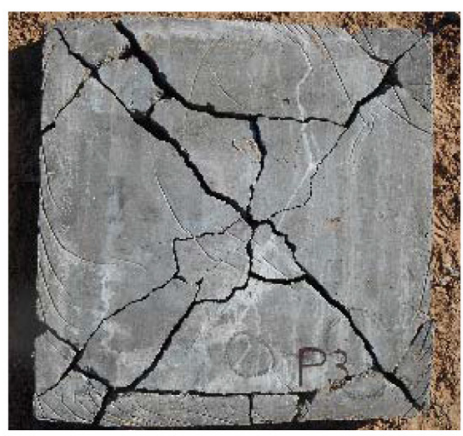

Concrete F40
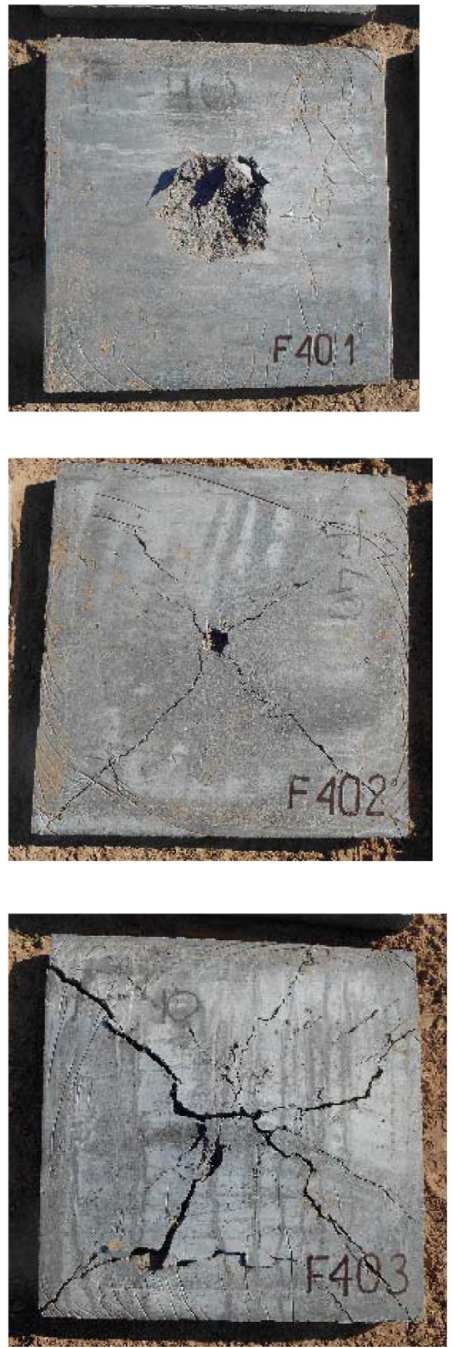

Concrete F80
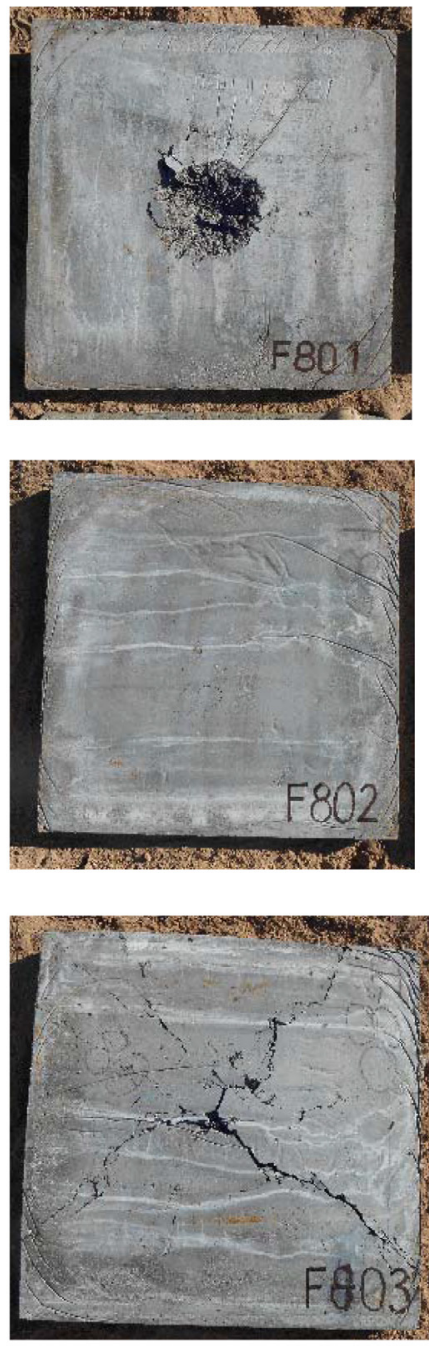

Fig. 9. Slabs rear face after blast tests.

Table 7

Slabs blast damage summary.

\begin{tabular}{|c|c|c|c|c|c|}
\hline Test type & Slab & Front face & $\begin{array}{l}\text { Observations on } \\
\text { Rear face }\end{array}$ & Lateral sides & $\begin{array}{l}\text { Front face max. residual deflection } \\
\text { [mm] }\end{array}$ \\
\hline \multirow[t]{3}{*}{ I } & P1 & Fractured & $\begin{array}{l}\text { Fractured Spalling zone: } \\
\quad 230 \mathrm{~mm} \times 260 \mathrm{~mm} \text {, depth } 50 \mathrm{~mm}\end{array}$ & Fractured & $>170$ \\
\hline & F401 & $\begin{array}{l}0.1 \mathrm{~mm} \text { cracks Small crater: } \\
50 \mathrm{~mm} \times 60 \mathrm{~mm} \text {, depth } 10 \mathrm{~mm}\end{array}$ & $\begin{array}{l}0.3 \mathrm{~mm} \text { cracks Spalling zone: } \\
165 \mathrm{~mm} \times 160 \mathrm{~mm} \text {, depth } 40 \mathrm{~mm}\end{array}$ & $0.1 \mathrm{~mm}$ vertical crack & - \\
\hline & F801 & $\begin{array}{l}0.1 \mathrm{~mm} \text { cracks Small crater: } 40 \mathrm{~mm} \text { x } \\
55 \mathrm{~mm} \text {, depth } 7 \mathrm{~mm}\end{array}$ & $\begin{array}{l}0.1 \mathrm{~mm} \text { cracks Spalling zone: } \\
150 \mathrm{~mm} \times 150 \mathrm{~mm} \text {, depth } 35 \mathrm{~mm}\end{array}$ & - & - \\
\hline \multirow[t]{3}{*}{ II } & P2 & Fractured & Fractured & Fractured & $>170$ \\
\hline & F402 & $\begin{array}{l}0.1 \mathrm{~mm} \text { cracks Very small crater: } \\
15 \mathrm{~mm} \times 15 \mathrm{~mm} \text {, depth } 3 \mathrm{~mm}\end{array}$ & $\begin{array}{l}2.5 \mathrm{~mm} \text { diagonal cracks Spalling zone: } \\
35 \mathrm{~mm} \times 35 \mathrm{~mm} \text {, depth } 10 \mathrm{~mm}\end{array}$ & - & $\sim 5$ \\
\hline & F802 & - & $0.2 \mathrm{~mm}$ cracks & - & - \\
\hline \multirow[t]{3}{*}{ III } & P3 & Fractured & Fractured & Fractured & $>170$ \\
\hline & F403 & $\begin{array}{l}3 \mathrm{~mm} \text { circular and diagonal cracks Cra- } \\
\text { ter: } 20 \mathrm{~mm} \times 20 \mathrm{~mm} \text {, depth } 3 \mathrm{~mm}\end{array}$ & $10 \mathrm{~mm}$ diagonal cracks & $2 \mathrm{~mm}$ diagonal cracks & 27.3 \\
\hline & F803 & $0.1 \mathrm{~mm}$ circular crack & $4 \mathrm{~mm}$ diagonal cracks & $1.5 \mathrm{~mm}$ diagonal cracks & 9.9 \\
\hline
\end{tabular}

increases between 12 and $15 \%$ of compression strength due to the addition of 0.5 to $2 \%$ of hooked end steel fibers ( $35 \mathrm{~mm}$ ) to HSC. Lu and Hsu [54] obtained an increase of 3\% of compression strength with the addition of $1 \%$ of hooked end steel fibers to HSC. Jatale and Mangulkar [55] found that compressive strength of a self compacting HSC is increased up to the $3 \%$ of fiber volume fraction and then decreases. The maximum increase depends on the fiber type (18\% for waved fibers $25 \mathrm{~mm}$ length, $13 \%$ for flat fibers $30 \mathrm{~mm}$ length, $9 \%$ for hooked end fibers $25 \mathrm{~mm}$ length). Experimental results from Marar et al. [56] showed that compressive strength of FRC and HSFRC increases with the fiber volume fraction increase. Matrix compression improvements were also found by other authors 
when adding shorter hooked end steel fibers [11] or straight steel micro fibers [36,57] to a mortar matrix, but Dawood and Ramli [58] and Wang et al. [17] concluded that, for a range of fiber volume fraction between $0.5 \%$ and $2 \%$ the influence of fiber content on compression strength is rather small. All these results are plotted in Fig. 10 for comparison.

Considering that in the present experiments the base concrete was the same in P, F40 and F80, the slight decrease in compression strength observed with the addition of fibers is attributed to a decrease in compaction due to a combined effect of a self compacting mixture, $60 \mathrm{~mm}$-long hooked fibers and the use of small molds.

When considering the flexure tests results (see Fig. 2), it can be observed that the stress-CMOD curves of plain concrete beams are almost coincident while, as expected, those corresponding to F40 and F80 present some dispersion. The scatter of flexure test results has also been reported by other authors [7,52] for the case of NC including hooked end steel fibers and it is due to the variation of the fiber content in the mid-span crack surface of beams made of the same concrete (see Table 3). The distribution of the fibers depends on fibers geometry, specimen size, fiber content and pouring method [55]. It should be mentioned that the dispersion in the bending response could have been increased in these tests as very thin specimens were used when compared to standard beams $(150 \mathrm{~mm}$ side) [7]. As usual, the dispersion is greater for the lower fiber content [52] and two groups of responses for F40 can be clearly identified in correspondence with the actual fibers contents registered in Table 3.

Plain concrete beams presented a very brittle response with a sudden drop of the load. The average flexure strength and the apparent fracture energy of this concrete can be indirectly estimated from these results [59], giving a flexure strength of $7.38 \mathrm{MPa}$ and an apparent fracture energy of $0.166 \mathrm{MPa} \mathrm{mm}$. The evolution of plain concrete flexure strength and apparent fracture energy with compression strength are plotted in Fig. 11 together with the results from previous experiments with NC and HSC [51,60,61]. These results present the same tendency reported by other authors for UHPC (without coarse aggregates) [36,62] except for the slight decay of apparent fracture energy for the HSC used in this paper. It can be observed that flexure strength presents an approximately linear increase with compression strength. But flexure strength and fracture energy are not increased proportionally to compression strength and, as a result, HSC is a very brittle material. Failure of plain concrete beams was characterized by one central fracture. Nevertheless, due to the locking effect of aggregates, the beams

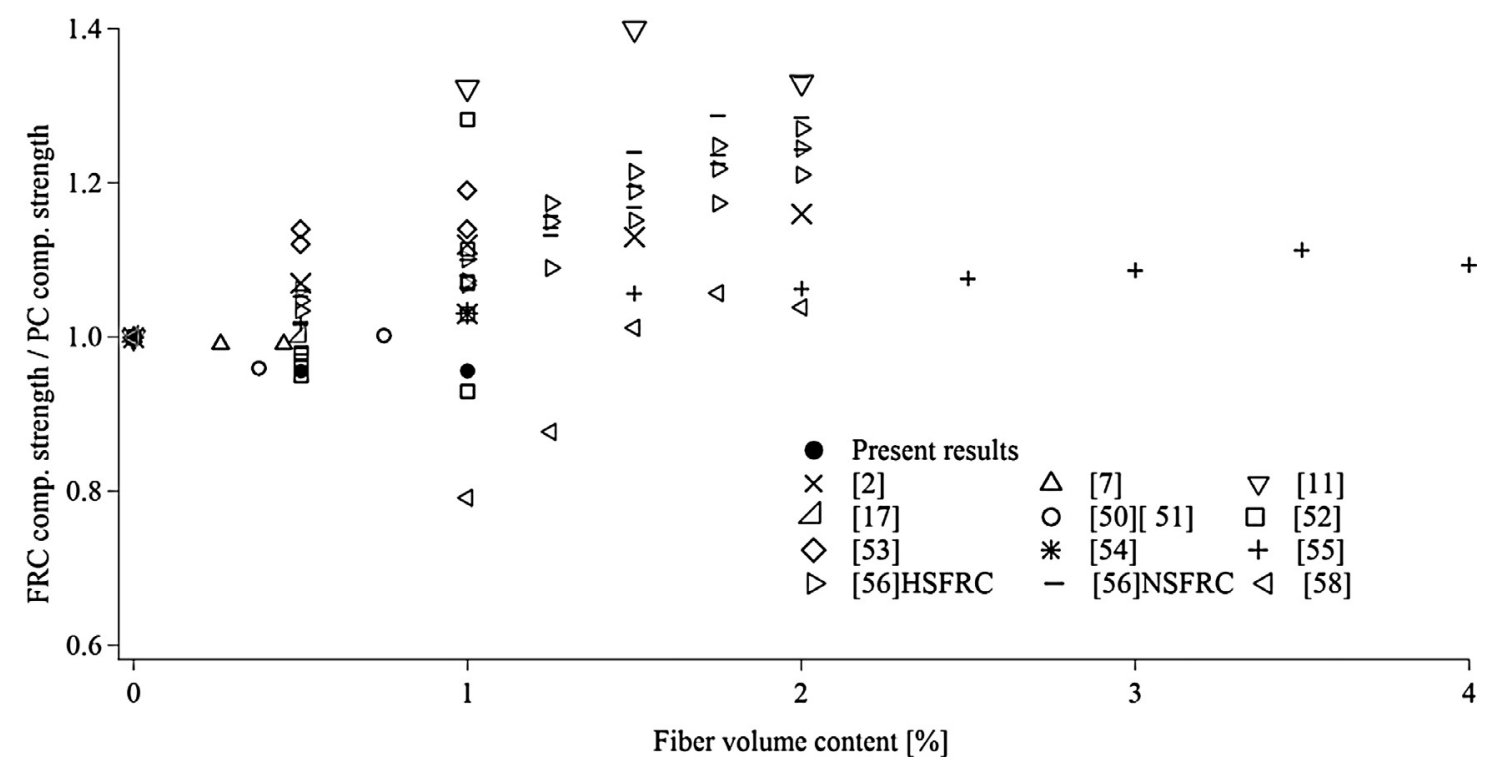

Fig. 10. Effect of fiber content on compression strength.
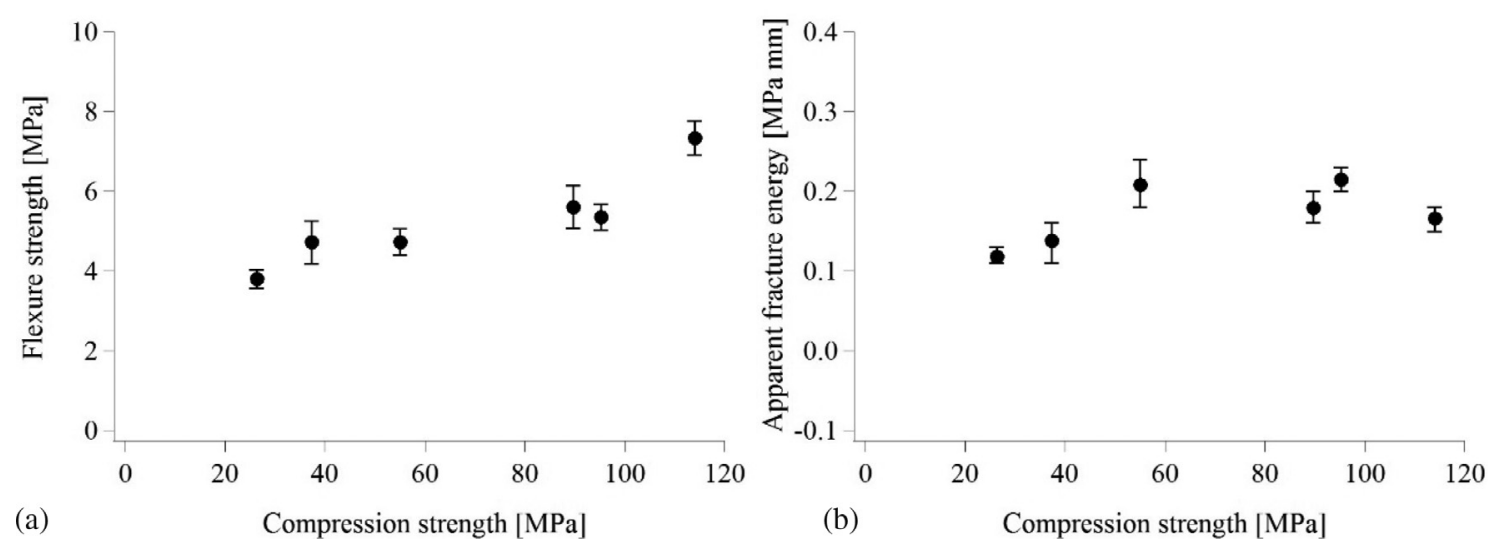

Fig. 11. Evolution of flexure properties with compression strength (average and standard deviation): (a) Flexure strength and (b) Apparent fracture energy. 
preserved their integrity after the tests that were continued up to CMOD values much greater than those shown in Fig. 2.

In the case of F40 beams, after a load drop and depending on actual fiber content, load-bearing capacity was recovered in some cases and over passed in other cases, showing strain hardening. For the beams with higher fiber content, F80, a strain hardening response with no softening up to very large displacements was always obtained. It is very interesting to note that crack patterns are in correspondence with these observations. In the case of F40 there is a predominant crack, while, even though there is a central notch, the strain hardening presented by F80 beams is characterized by the appearance of several cracks at both sides of central section. After unloading, all fiber reinforced beams showed very low deformation recovering because pulled out fibers prevent crack closure.

The evolution of strength parameters with fiber density in the crack section is shown in Fig. 12. The corresponding stress values, $f_{\mathrm{L}}, f_{\text {max }}, f_{\mathrm{R} 1}$ and $f_{\mathrm{R} 3}$ were previously defined in Section 2.2.1 when Table 3 was presented. While the first peak stress $f_{\mathrm{L}}$ (more related to the base matrix strength) is not affected by the fiber content, the post peak parameters are strongly dependent on the fiber density on the fracture surfaces.

The evolution of average relative flexural strength and average relative fracture energy with fiber content is presented in Fig. 13 together with the results previously obtained by the authors [60] for HSC with hooked end low carbon steel fibers. It should be noted that high strength steel fibers are more efficient improving flexure response because they do not break during pull-out. The slope of the flexure strength vs fiber content curve slightly increases with fiber

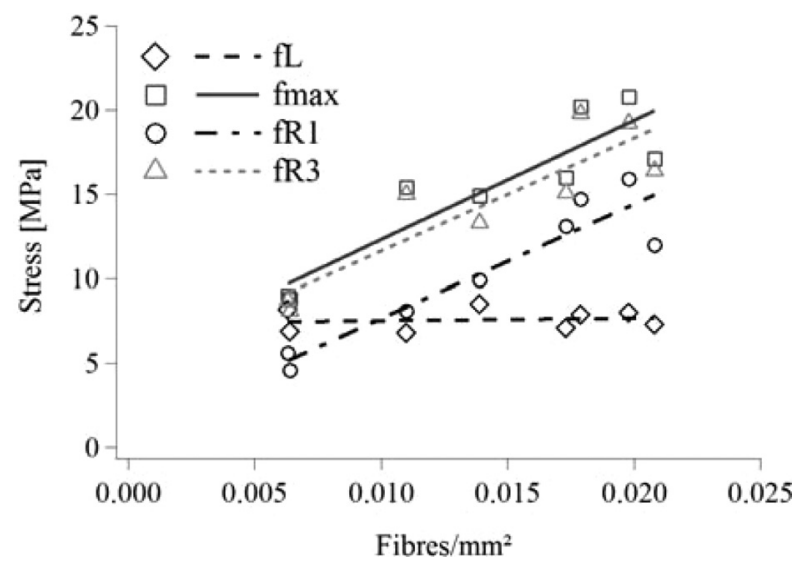

Fig. 12. Effect of fiber content on the bending strength parameters. content. The same tendency has been reported by Yu et al. [57] for UHPFRC (short straight steel fibers). In contrast, Thoma et al. [36] and Millard et al. [4] concluded that the effect of short straight steel fiber content on UHPFRC flexure strength reduces for percentages greater than $1 \%$ in volume.

The results in Fig. 13 corresponding to hooked end steel fibers show significantly higher improvements of flexural strength and toughness than those obtained by other authors for NC with the same contents of hooked end steel fibers [52], HSC with greater content of straight shorter steel fibers (30 mm length) [58] and UHPC with the same content of short straight steel fibers $[4,10,36,57,63]$.

The static tests on slabs presented in Fig. 4 and 5 show the influence of fibers. Although only one test was performed for each type of mixture and the results are only indicative, they are coherent with those obtained on beams. For the case of plain concrete $(P)$ the first abrupt load drop corresponds to the occurrence of the first flexure crack and the second peak followed by another drop corresponds to the occurrence of a second crack in the orthogonal direction. In this test, the slab was originally supported on its four sides. Once the first crack appeared, the slab began to work in only one direction, as two independent parallel slabs, until it is cracked in the orthogonal direction. Fig. 4(b) also shows that the cracking load of slab F40 was almost the same as that of slab P but, in this case, after the first cracking load, the load bearing capacity increased due to the presence of fibers that led to the development of cracks in different directions. When the fiber content was doubled (F80), the initial cracking load was significantly higher and it continued increasing evidencing thus multiple crack formation as it was observed on F80 prism tests. Contrary to F40, neither load drop nor sudden increase in deflection could be appreciated. In F80 the maximum load was achieved for a deflection greater than $10 \mathrm{~mm}$ maintaining a residual capacity that was practically twice the load bearing capacity of plain concrete slab. For deflections higher than $5 \mathrm{~mm}$, the difference between the response of slabs with both fibers contents $(0.5 \%$ and $1 \%$ in volume) was not so important. Although only one test was performed for each mixture, this result indicates that medium fiber contents $(\sim 0.5 \%)$ are enough to produce significant toughness increase.

The photographs in Fig. 5 show the top and bottom slab faces at the end of the static flexure tests. While in the case of the plain concrete slab there are two well defined cracks that completely split the slab in four pieces, in the case of F40 and F80, distributed crack patterns are observed and the slabs preserved integrity after the flexure tests.

Regarding the complementary pull-out tests, the average loaddisplacement curve in Fig. 6 presents the characteristic shape usually observed with hooked end steel fibers [15]. No fiber break was observed during pull-out tests; the fiber strength is enough to
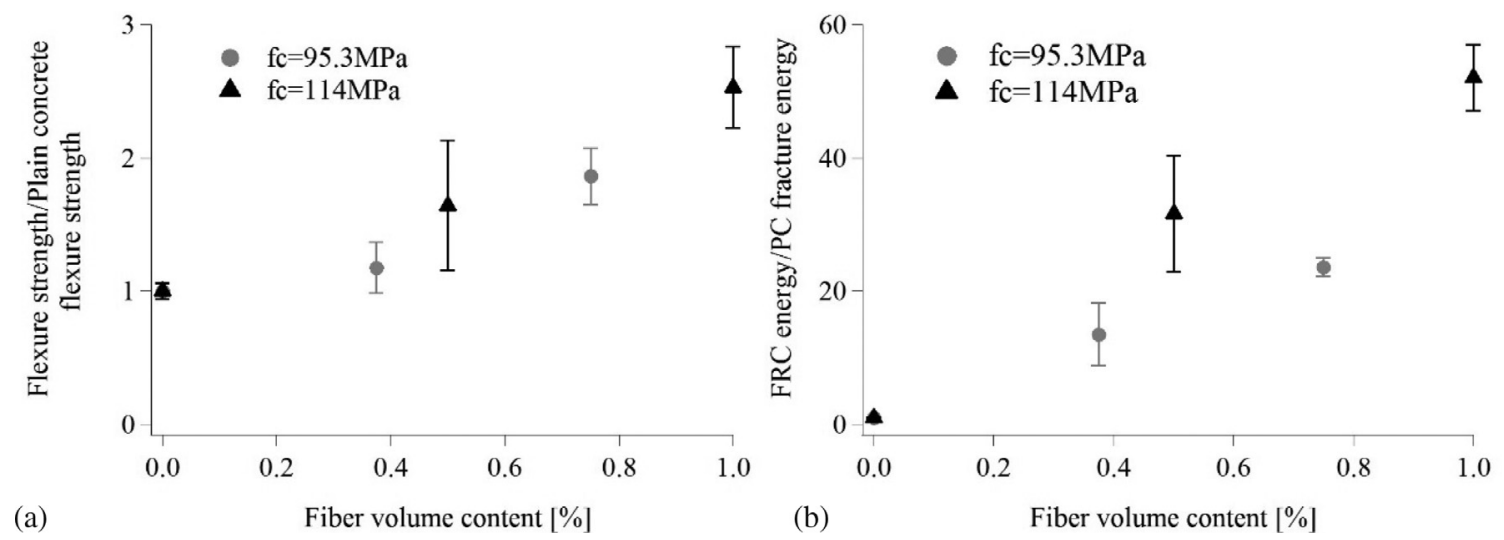

Fig. 13. Evolution of flexure properties with fiber content (average and standard deviation): (a) Flexure strength and (b) Energy dissipation capacity. 
produce a slip-failure mechanism in the high strength matrix analyzed. The maximum pull-out load corresponds to a stress of $2020 \mathrm{MPa}$ that is lower than the fiber's strength. This is an essential condition to provide optimum behavior of the resulting HSFRC.

Pull-out tests of the same fibers in normal strength mortar M30 (compression strength $=30 \mathrm{MPa}$ ) and other HSC, C90 (Compression strength $=90 \mathrm{MPa}$ ) have been previously carried out by the authors $[15,51]$. The comparison of average load displacement curves corresponding to different matrix strengths are presented in Fig. 14 where the results indicated with $\mathrm{C} 114$ correspond to the pull-out tests from the HSC with compression strength equal to $114 \mathrm{MPa}$ reported in this paper.

It can be seen that the anchorage effect and the friction effect increase with matrix strength but the influence of matrix strength on pull-out strength is gradually reduced with the matrix strength increase. In coincidence with the results from pull-out tests of hooked still fibers of $30 \mathrm{~mm}$ length obtained by Abu-Lebdeh et al. [64], the curves in Fig. 14 suggest that for this type of fibers the pullout work is more sensitive to the matrix strength than the peak load. As it was mentioned, and in coincidence with previous results reported in the literature [19,64-71], no appreciable strain rate effect was found in pull-out responses for extraction velocities up to $500 \mathrm{~mm} / \mathrm{min}(8.33 \mathrm{~mm} / \mathrm{s})$.

As fiber pull-out is the principal mechanism defining de material toughness, many researchers have studied the effect of loading rate on fibers pull-out response [19]. In the case of hooked end steel fibers, the pull-out load is borne by adhesion and anchorage effects. However, the contribution of adhesion is lower than anchorage effect provided by the hook. Anchorage effect begins with the deformation of the matrix surrounding the hook and continues until the fiber yield strength is reached. Anchorage effect depends on matrix microcracking and fiber yielding strength. When the fiber is straightened, the pull-out resistance is provided by frictional effects [66]. Thus, the pull-out strength of hooked end steel fibers from cementbased matrices depends on many factors like the matrix mechanical properties, the fiber mechanical properties and geometry and the fiber-matrix bond and frictional strength. Most of the mechanical properties of the matrix and the fibers depend on the loading rate, so it is expected that the pull-out response also shows rate sensitivity but the experimental results available for different materials and velocities are not all coincident.

Gokoz and Naaman [65] concluded that the peak pull-out load for straight steel fibers from a mortar matrix was insensitive to loading rate up to $500 \mathrm{~mm} / \mathrm{s}$ and no conclusions could be stated for greater strain rates. Moreover, they also concluded that the post peak response that is representative of the friction mechanism is also almost independent of loading rate. Kim et al. [68] found that

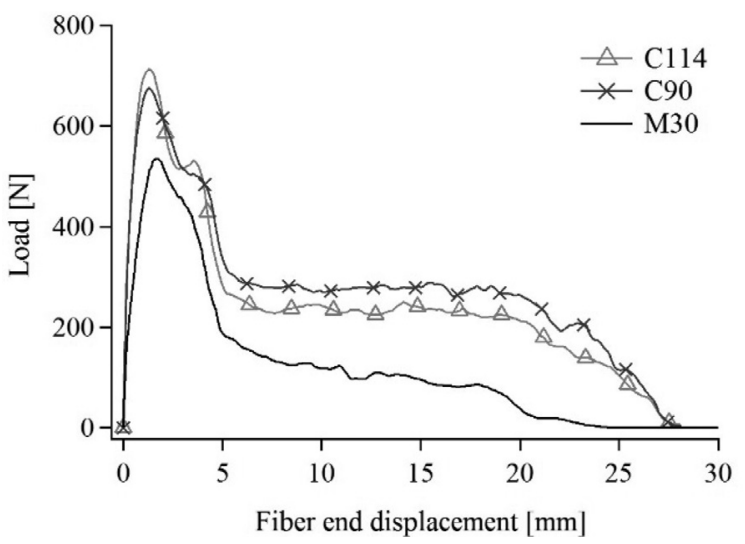

Fig. 14. Comparison of fiber pull-out response from different strength mortars. hooked end steel fibers did not present rate sensitivity for lower pull-out velocities (up to $18 \mathrm{~mm} / \mathrm{s}$ ) and they attributed this result to the localization of micro-cracking, that is the main source of strain rate sensitivity, in a small area surrounding the hooks. In contrast, Abu-Lebdeh et al. [69], Xu et al. [70] and Tai et al. [71] found increases in pull out strength and pull-out work for hooked end steel fibers extracted from very high strength concrete matrix at velocities corresponding to the seismic range $(18-24.5 \mathrm{~mm} / \mathrm{s})$. Tai et al. [71] attributed the differences with Kim et al.s [68] results to the greater strength of the concrete matrix used in their tests. On the other side, Banthia and Trottier [66] found that, at very high strain rates $(1500 \mathrm{~mm} / \mathrm{s})$, the pull-out strength and energy of deformed steel fibers are greater than static pull-out strength and energy providing that the fiber failure mode does not change with the loading velocity increase.

The previous observations can be used to explain the experimental results reported in this paper. It should be observed that the pullout velocities used in these tests (up to $8.3 \mathrm{~mm} / \mathrm{s}$ ) are less than those used by Banthia and Trottier [66] and those used by Kim et al. [68], Abu-Lebdeh et al. [69] and Tai et al. [71] to represent typical seismic strain rates. Additionally, the matrix strength (114 MPa) is lower than those used by Abu-Lebdeh et al. [69] (133-196 MPa) and Tai et al. [71] (184.9 MPa). Moreover, for the fibers analyzed $(0.7 \mathrm{~mm}$ diameter) the maximum strain rate in the fiber corresponding to a pull-out rate of $8.33 \mathrm{~mm} / \mathrm{s}$ is approximately $1.51 / \mathrm{s}$ [51] and steel rate sensitivity is rather low for this strain rate. These facts explain why pull-out rate does not increase for velocities up to $500 \mathrm{~mm} / \mathrm{min}$ $(8.33 \mathrm{~mm} / \mathrm{s})$. On the other side, in coincidence with the results presented by Gokoz and Naaman [65], the frictional part of the pull-out response is not either affected by the loading rate.

\subsection{Blast tests results}

The blast tests results clearly show the different types of concrete failure previously mentioned and the effect of fibers addition on blast response.

Independently on the explosive mass and stand-off distance, all tests performed on plain concrete produced brittle flexure failure of the slabs, see Fig. 8 and 9. The slabs were completely split in many parts by diagonal fractures. The increasing energy of explosions Types I to III is evidenced by the final location of the slabs fragments some of which have flown out and are lying in the surroundings of the slabs supports (see Fig. 8). It is also observed that additional fractures appeared near slab corners that were prevented to move by the angles at the steel support corners (see Fig. 8). Circular fractures typical of clamped plates were also developed (see Fig. 8 and 9).

The flexure failure of HSC slabs, even under small contact blast loads, is explained by the reduced slab thickness and the brittle nature of HSC that was also evident in the quasi-static flexure response. In blast test Type I that corresponds to a small contact explosion, flexure failure of plain concrete slab was accompanied by an important concrete spalling at the rear face. Due to the fracture of front face, concrete erosion cannot be distinguished on the upper surface.

The damage patterns obtained for HSFRC slabs F40 and F80 were strongly different from those of HSC slabs. Slabs F401 and F801 tested under contact explosions did not exhibit flexure failure and they preserved integrity after the tests (see Fig. 8 and 9). Flexure cracks could not be identified. The front faces of the slabs presented a small eroded zone like a crater produced by the high pressures originated by the detonation of the explosive in contact with concrete. Small pieces of concrete have been thrown out by the blast pressure and have later fell down on the slab. A zoom of the eroded zone of slab F801 is presented in Fig. 15 where the fibers can be identified showing that some of the hooks have been straightened. 


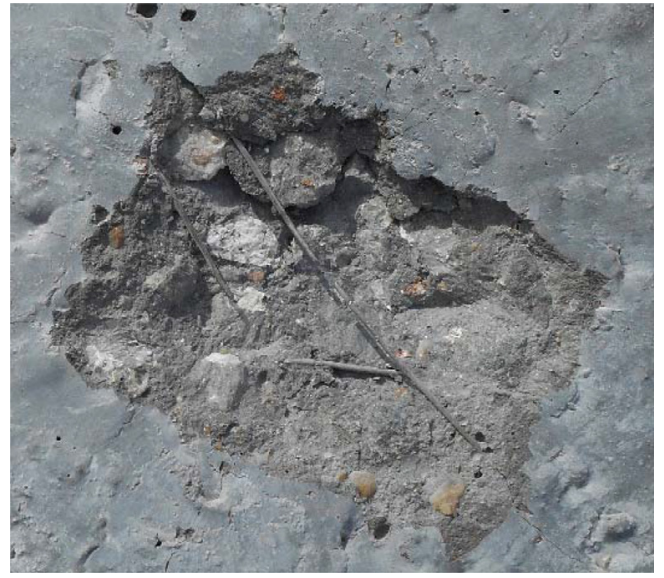

Fig. 15. Eroded zone of slab F801.

The dimensions of the front face eroded zone of the slabs subjected to the same contact blast loads are presented in Table 7. The crater dimensions are reduced when fibers are added but the reduction is not proportional to the fiber content. Only a slight reduction of crater dimensions was obtained when doubling the fiber volume content. This result suggests that the contribution of the long fibers to erosion strength is less than the contribution to flexural strength.

On the other side, both HSFRC slabs subjected to contact explosions presented rear face concrete spalling. The contribution of fibers preventing concrete spalling is evident from the comparison of the dimensions of the rear face spalling zone of slabs P1, F401 and F801 (Figs. 9 and 16 and Table 7). The distribution of fibres in the slabs plane can be clearly observed in Fig. 16. It can also be seen that most of the fibers hooks have not been straightened.

Concrete spalling is a result of tension stresses so improvements and prevention of this phenomenon are expected to be found when increasing fiber content. Nevertheless, it should be observed that when a $0.5 \%$ of fibers is added the dimensions of the spalling zone are reduced $32 \%$ with respect to HSC, while the addition of twice this fiber content only produces an additional reduction of $5 \%$ in spalling zone dimensions. This result confirms that even moderate long steel fibers contents are enough to improve the tension strength of the matrix and the behavior of HSC under this type of loads but the improvements are less effective than those observed in flexure response because the pull-out mechanism, more precisely the anchorage effect of the fibers has not been developed.

Residual deflection of HSFRC slabs under contact blast loads could not be appreciated, both slabs remained almost plane.

While for blast test Type II that corresponds to a smaller scaled distance (see Table 7) P2 slab was fractured, F402 slab presented flexure cracks and slab F802 did not exhibit any flexure crack, see Fig. 8. Once again, this result clearly illustrates the effect of fiber addition and fiber content on blast response.

Diagonal cracks are evident on rear face of slab F402 (see Fig. 9) and, in spite of them, the slab preserved its integrity because the cracks are crossed by the fibers that prevented their opening. These cracks are flexure cracks and were evidently caused by the positive phase of the blast wave acting on the front face. Negative phase of the blast wave, that is always smaller than the positive phase, was not enough to crack the front face. The photograph of F402 front face in Fig. 8 shows the slab covered by dust originated from the ground. Nevertheless, it can be seen that the direct pressure acting on the front face produced erosion in a reduced zone and a bigger spalling zone was created in the rear face (Fig. 9). Both damaged zones are smaller than those produced by the contact explosion.

The same explosion only produced almost imperceptible cracks on slab F802 rear face showing the effect of increasing the fiber content on flexure crack and spalling control. Additionally, while small permanent deflection was exhibited by slab F402, no permanent deflection was registered in slab F802.

For the case of blast test Type III corresponding to a smaller scaled distance than blast test Type II, the three slabs exhibited flexure cracks. While slab P3 was fractured, slab F403 presented wide flexure cracks controlled by the fibers on both faces and slab F803 presented very thin flexure cracks on the front face. The cracks in the slab F803 rear face were much thinner than those in slab F403. The effect of fiber addition and content is again evident in these results. The beneficial effect of fiber addition can also be appreciated in the reduction of permanent deflection to one third when the fiber content was doubled. The permanent deflection of slab F403 can be clearly identified in front face where also circular cracks produced by the clamping effect provided by the supports can be seen (Fig. 8). It is interesting to observe in Fig. 17 the diagonal cracks in the laterals sides of slabs F403 and F803. These cracks appeared in the four lateral sides and they are sewed by the steel fibers. Their orientation suggests that they are shear cracks produced by the slabs vibration and induced by the corner supports.

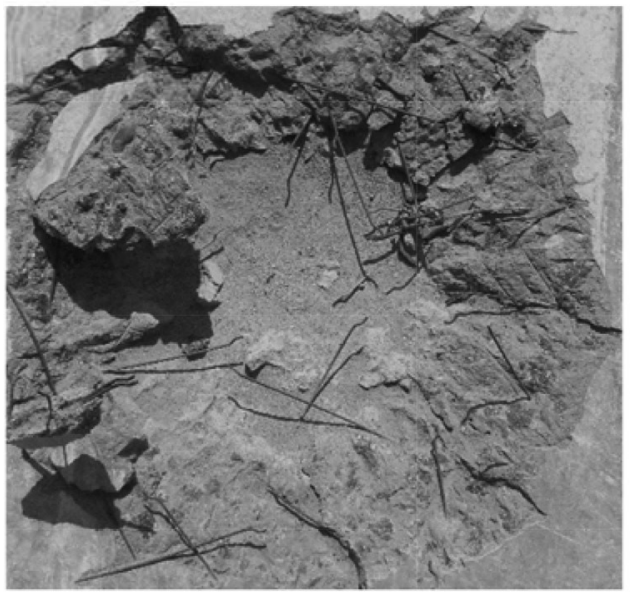

(a)

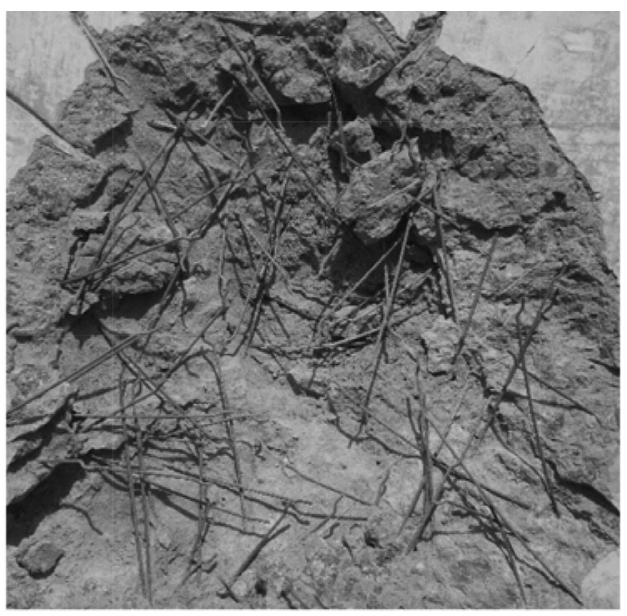

(b)

Fig. 16. Spalling zone: a) Slab F401 and b) Slab F801. 


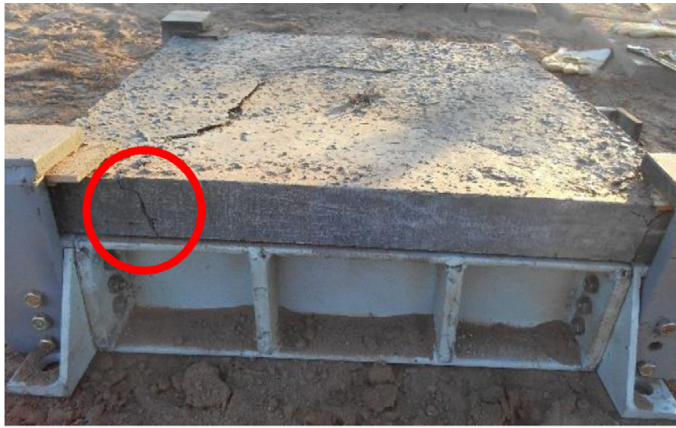

(a)

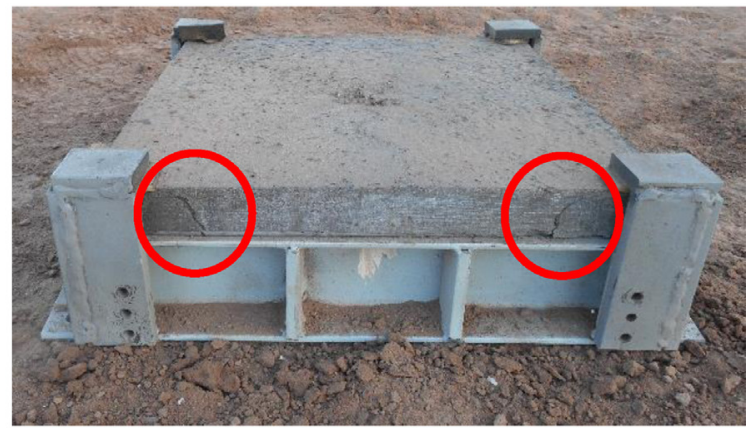

(b)

Fig. 17. Diagonal cracks in slabs lateral sides: (a) F403 and (b) F803.

There are some general common conclusions regarding blast performance of the HSFRC studied in this paper and the results obtained by other authors for FRC, HSFRC and UHPFRC including different types of fibers. In this paper the blast performance of the HSC matrix was observed to be significantly improved by the addition of long hooked end steel fibers bridging the cracks and increasing energy absorption capacity similarly to the results presented by other authors for steel FRC [21], for polyvinyl alcoholic FRC, polyethylene FRC, and polypropylene FRC [22], for hybrid steel FRC [34], for HSFRC with steel fibers [30] and UHPFRC with short straight steel fibers [38]. In coincidence with the observations of Mao et al. [31] for UHPFRC, the scaled distance to produce total failure diminishes with the increase of fiber content. Moreover, midpoint deflections of slabs that did not fail are also reduced with the increase of fiber contents. This result is coincident with the results obtained by Schenker et al. [29] for HSFRC slabs and Christian and Chye [30] for reinforced HSFRC (steel fibers) and steel composite slabs.

As stated by Wang et al. [72] for FRC with ultra-short steel fibers under impact load, Ohtsu et al. [22] for polyvinyl alcoholic FRC, polyethylene FRC, and polypropylene FRC slabs and Coughlin et al. [20] for carbon, nylon and mix steel and synthetic barriers under contact blast loads, the dimensions of the crater formed in the front face of the slabs are reduced with the addition of fibers but the improvement is less important than that observed in flexural cracking control.

As it was observed by other authors for concretes incorporating long steel fibers [21], polyvinyl alcoholic, polyethylene and polypropylene fibers [22], polyethylene fibers [24], nylon fibers [20] and HSC with steel fibers [29], the long steel fibers used in this paper reduce the spalling zone dimensions.

In coincidence with the conclusions of Coughlin et al. [20], for certain fiber content the increase of fiber volume does not improve spalling resistance significantly.

\section{Conclusions}

The effect of incorporating different contents of $60 \mathrm{~mm}$ length hooked end high carbon steel fibers in a $114 \mathrm{MPa}$ concrete on static and blast tests response was studied. From the analysis and comparison of test results the following conclusions can be stated.

As expected, the incorporation of fibers leads to significant increases in residual loading capacity and toughness under static loads. Multiple crack formation took place in prisms bending tests mainly for the higher fiber contents ( $1 \%$ in volume). This characteristic behavior was also verified in slab tests, where a great branching of cracks was observed.

Blast behavior is significantly improved by the addition of fibers. Flexural cracks width, erosion zone and spalling zone dimensions and permanent deflections are reduced with the increase of fiber content. Many interesting findings of these experiments are presented as follows.

The addition of fibers to HSC can change the blast response, type of damage and failure of the slabs, preserving their integrity. Plain HSC slabs could not withstand any of the blast tests; they were completely fractured due to the brittleness of HSC. For the case of contact blast, the addition of $0.5 \%$ fibers is enough to change the failure mode preventing flexure failure. For close blast loads, the scaled distance that produces flexural cracks decreases with the increase of fiber content. This result is due to the increase of flexural strength and toughness also observed in static tests. Cracks are bridged by the fibers that prevent their opening.

The effect of long fiber content on crater and spalling zone dimensions is less important than the effect on flexural response where a localized fracture sewed by the fibers is produced. The crater in the front face is produced by the high compression pressures that erode the matrix producing a smeared damage. A moderate amount of long fibers can help increasing triaxial compression strength of the matrix but once the matrix is eroded around the fibers, they cannot control the crater formation in the same way that they can control a crack sewing its lips, because the entire matrix surrounding the fibers is disintegrated. Similarly, spalling is produced by tension stress states that lead to a distributed failure of the matrix. A small amount of long fibers can improve tension strength of the matrix but once the matrix fails around the fibers, they are loosened and, consequently, their effectiveness is lost in this zone.

The long hooked end steel fibers used in the tests have shown to be very effective to improve HSC static and blast behavior. As usual, the fibers were mainly oriented in the plane of the slabs; in this case the orientation can be more marked due to the length of the used fibers and could have helped the improvement of the slabs static and blast behavior. The effects of using shorter hooked end steel fibers and short straight fibers and the blend of different types of fibers will be subject of further research. Particularly, the effectiveness of different types of fibers controlling erosion in contact explosion and spalling in rear face will be further studied.

It must be emphasized that the results obtained from blast loads acting on the thin slabs studied in this paper are only indicative of the effect of fibers on blast response. The results cannot be directly extrapolated to actual dimension structural elements because the material has not been scaled down for the tests. On the other side, blast structural response cannot be scaled down because, in contrast to pressure values, impulse values are not only functions of the scaled distance but also of the explosive mass. Full scale structural elements should be tested to quantify the improvements provided by the fibers. 


\section{Acknowledgements}

The authors wish to thank the financial support of National Agency for Scientific and Technological Promotion (BID PICT 2013 1740), National Scientific and Technological Research Council (CONICET) (Project PIP 2015-2017 112201501008 61CO), LEMIT-CIC, National University of Tucumán research Council (CIUNT) (PIUNT 26E/520), National University of La Plata (UNLP) (Project 11/I188), National University of Cuyo (UNCu) and Ms. Amelia Campos for the English revision. The firms Cementos Avellaneda S.A., Ferrocement S. A. and Sika Argentina S.A.I.C. that provided the cement, the silica fume and the chemical admixtures are also greatly acknowledged.

\section{References}

[1] Brandt AM. Fibre reinforced cement-based (FRC) composites after over 40 years of development in building and civil engineering. Compos Struct 2008;86:3-9.

[2] Song PS, Hwang S. Mechanical properties of high-strength steel fiber-reinforced concrete. Constr Build Mater 2004;18:669-73.

[3] Kustermann A, Thienel K-C, Bludau C, Keuser M, Zimbelmann R. Protection elements made of High Strength Fiber Reinforced Concrete (HSFRC) as single and multi layer constructions. In: Prooceedings of the 12th international symposium on interaction of the effects of munitions with structures; New Orleans, USA, 2005.

[4] Millard SG, Molyneaux TC, Barnett SJ, Gao X. Dynamic enhancement of blastresistant ultrahigh performance fibre-reinforced concrete under flexural and shear loading. Int J Impact Eng 2010;37:405-13.

[5] Banthia N, Nandakumar N. Crack growth resistance of hybrid fiber reinforced cement composites. Cement Concrete Comp 2003;25:3-9.

[6] Yao W, Li J, Wu K. Mechanical properties of hybrid fiber-reinforced concrete at low fiber volume fraction. Cement Concrete Res 2003;33:27-30.

[7] Buratti N, Mazzotti C, Savoia M. Post-cracking behaviour of steel and macro-synthetic fibre-reinforced concretes. Constr Build Mater 2011;25:2713-22.

[8] Sawant RM, Ghugal YM, Khan JA. Evaluation of split tensile strength of high strength fiber reinforced concrete. Int J Tech Res Applications 2015;3(6):243-7.

[9] Annadurai A, Ravichandran A. Flexural behavior of hybrid fiber reinforced high strength concrete. Indian J Sci Technol 2016;9(1):1-5.

[10] Kim DJ, Park SH, Ryu GS, Koh KT. Comparative flexural behavior of hybrid ultra high performance fiber reinforced concrete with different macro fibers. Constr Build Mater 2011;25:4144-55.

[11] Sirijaroonchai K, El-Tawil S, Parra-Montesinos G. Behavior of high performance fiber reinforced cement composites under multi-axial compressive loading. Cement Concrete Comp 2010;32:62-72.

[12] Tran TK, Kim DJ. High strain rate effects on direct tensile behavior of high performance fiber reinforced cementitious composites. Cement Concrete Comp 2014; $45: 186-200$.

[13] Tran NT, Tran TK, Kim DJ. High rate response of ultra-high-performance fiberreinforced concretes under direct tension. Cement Concrete Res 2015;69:72-87.

[14] Yoo DY, Kang S-T, Yoon Y-S. Effect of fiber length and placement method on flexural behavior, tension-softening curve, and fiber distribution characteristics of UHPFRC. Constr Build Mater 2014;64:67-81.

[15] Isla F, Ruano G, Luccioni B. Analysis of steel fibers pull-out. Experimental study. Constr Build Mater 2015;100:183-93.

[16] Shah AA, Ribakov Y. Review. Recent trends in steel fibered high-strength concrete. Mater Design 2011:32:4122-51.

[17] Wang S, Zhang M-H, Quek ST. Mechanical behavior of fiber-reinforced highstrength concrete subjected to high strain-rate compressive loading. Constr Build Mater 2012;31:1-11

[18] Tran TK, Kim DJ. Investigating direct tensile behavior of high performance fiber reinforced cementitious composites at high strain rates. Cement Concrete Res 2013;50:62-73.

[19] Caverzan A, Cadoni E, di Prisco M. Tensile behaviour of high performance fibrereinforced cementitious composites at high strain rates. Int J Impact Eng 2012; $45: 28-38$

[20] Coughlin AM, Musselman ES, Schokker AJ, Linzell DG. Behavior of portable fiber reinforced concrete vehicle barriers subject to blasts from contact charges. Int J Impact Eng 2010;37:521-9.

[21] Lan S, Lok T-S, Heng L. Composite structural panels subjected to explosive loading. Constr Build Mater 2005;19:387-95.

[22] Ohtsu M, Uddin F, Tong W, Murakami K. Dynamics of spall failure in fiber reinforced concrete due to blasting. Constr Build Mater 2007;21:511-8.

[23] Wang ZL, Konietzky H, Huang RY. Elastic-plastic-hydrodynamic analysis of crater blasting in steel fiber reinforced concrete. Theor Appl Fract Mec 2009;52: 111-6.

[24] Yamaguchi M, Koji T, Yoshiyuki M. An experimental study on blast resistance of polyethylene fiber reinforced concrete. J Temporal Des Archit Environ 2009;9:158-61.

[25] Pantelides CP, Garfield TT, Richins WD, Larson TK, Blakeley JE. Reinforced concrete and fiber reinforced concrete panels subjected to blast detonations and post-blast static tests. Eng Struct 2014;76:24-33.
[26] Foglar M, Kovar M. Conclusions from experimental testing of blast resistance of FRC and RC bridge decks. Int J Impact Eng 2013;59:18-28.

[27] Agardh L. Fe-modeling of fibre reinforced concrete slabs subjected to blast load. J. Physic IV France 1997;7:723-8.

[28] Zhou XQ, Kuznetsov VA, Hao H, Waschl J. Numerical prediction of concrete slab response to blast loading. Int J Impact Eng 2008;35:1186-200.

[29] Schenker A, Anteby I, Gal E, Kivity J, Nizri E, Sadot O, et al. Full-scale field tests of concrete slabs subjected to blast loads. Int J Impact Eng 2008;35:184-98.

[30] Christian A, Chye GOK. Performance of fiber reinforced high-strength concrete with steel sandwich composite system as blast mitigation panel. Procedia Eng 2014;95:150-7.

[31] Mao L, Barnett SJ, Tyas A, Warren J, Schleyer GK, Zaini SS. Response of small scale ultra high performance fibre reinforced concrete slabs to blast loading. Constr Build Mater 2015;93(15):822-30.

[32] Aoude H, Dagenais FP, Burrell RP, Saatcioglu M. Behavior of ultra-high performance fiber reinforced concrete columns under blast loading. Int J Impact Eng 2015;80:185-202.

[33] Ngo T, Mendis P, Krauthammer T. Behavior of ultrahigh-strength prestressed concrete panels subjected to blast loading. J Struct Eng 2007;133(11):1582-90.

[34] Wu C, Oehlers DJ, Rebentrost M, Leach J, Whittaker AS. Blast testing of ultrahigh performance fibre and FRP-retrofitted concrete slabs. Eng Struct 2009;31: 2060-9

[35] Barnett S, Millard S, Tyas A, Schleyer G. Blast tests of fibre-reinforced concrete panels. Proc ICE Constr Mater 2010;163(3):127-9.

[36] Thoma K, Stolz A, Millon O. Performance and suitability of ultra-high-performance concrete under a broad range of dynamic loadings. In: Hao H, Li Z-X, editors. Advances in protective structures research. London: London Taylor \& Francis; 2012. p. 65-96. IAPS Special publication 1. Chapter 3.

[37] Yi NH, Kim JHY, Han TS, Cho YG, Lee JH. Blast-resistant characteristics of ultrahigh strength concrete and reactive powder concrete. Constr Build Mater 2012;8:694-707.

[38] Li J, Wu Ch, Hao H, Su Y. Investigation of ultra-high performance concrete under static and blast loads. Int J Protective Struct 2015;6(2):217-35.

[39] Luccioni B, Ruano G, Isla Calderón F, Zerbino R, Giaccio G. A simple approach to model SFRC. Constr Build Mater 2012;37:111-24.

[40] ASTM C231 / C231M - 14, Standard test method for air content of freshly mixed concrete by the pressure method. Book of Standards. Volume 04.02 DOI: 10.1520/C0231 C0231M-17

[41] ASTM C469/ C469M - 14 Standard test method for static modulus of elasticity an Poisson's ratio of concrete in compression. Book of Standards. Volume 04.02 DOI:10.1520/C0469_C0469M.

[42] Fédération Internationale du Béton, fib. Model code for concrete structures 2010. Berlin, Germany: Ernst \& Sohn; 2013.

[43] EN 14651:2005. Test method for metallic fibered concrete - Measuring the flexural tensile strength (limit of proportionality (LOP), residual). Brussels: CENEuropean Committee for Standardization; 2005. p. 1-17.

[44] Giaccio G, Tobes JM, Zerbino R. Use of small beams to obtain design parameters of fibre reinforced concrete. Cement Concrete Comp 2008;30(4):297-306.

[45] BS EN14488-5:2006. Testing sprayed concrete. Part 5: determination of energy absorption capacity of fibre reinforced slabs specimens. British Standards Institution; 2006

[46] Li J, Hao H. Numerical study of concrete spall damage to blast loads. Int J Impact Eng 2014;68:41-55.

[47] Codina R, Ambrosini D, de Borbón F. Alternatives to prevent the failure of RC members under close-in blast loadings. Eng Fail Anal 2016;60:96-106.

[48] ANSYS. AUTODYN Version 15.0.7 User's Manual. 2014.

[49] U.S. Department of Defense (DoD). Structures to resist the effects of accidenta explosions (UFC 3-340-02). Washington, DC: U.S. Department of Defense; 2008.

[50] Ruano G, Isla F, Isas Pedraza R, Sfer D, Luccioni B. Shear retrofitting of reinforced concrete beams with steel fiber reinforced concrete. Constr Build Mater 2014;54:646-58.

[51] Isla F. Fiber reinforced concrete model PhD Thesis. Argentina: Nat. Univ. Tucumán; 2014

[52] Caggiano A, Cremona M, Faella C, Lima C, Martinelli E. Fracture behavior of concrete beams reinforced with mixed long/short steel fibers. Constr Build Mater 2012;37:832-40.

[53] Nili M, Afroughsabet V. Combined effect of silica fume and steel fibers on the impact resistance and mechanical properties of concrete. Int J Impact Eng 2010;37:879-86

[54] Lu X, Hsu CTT. Behavior of high strength concrete with and without steel fiber reinforcement in triaxial compression. Cement Concrete Res 2006;36:1679-85.

[55] Jatale VB, Mangulkar MN. Performance of self compacting high strength fiber reinforced concrete (SCHSFRC). IOSR J Mech Civ Eng 2013;7(4):37-41.

[56] Marar K, Erenb O, Yitmena I. Compression specific toughness of Normal Strength Steel Fiber Reinforced Concrete (NSSFRC) and High Strength Steel Fiber Reinforced Concrete (HSSFRC). Mater Res 2011;14(2):239-47.

[57] Yu R, Spiesz P, Brouwers HJH. Mix design and properties assessment of UltraHigh Performance Fibre Reinforced Concrete (UHPFRC). Cement Concrete Res 2014;56:29-39.

[58] Dawood E, Ramli M. Mechanical properties of high strength flowing concrete with hybrid fibers. Constr Build Mater 2012;28(1):193-200.

[59] RILEM 50-FMC Committee (Fracture Mechanics of Concrete). Determination of the fracture energy of mortar and concrete by means of three-point bend tests on notched beams. Mater Struct 1985;18(106):285-90.

[60] Ruano G, Isla F, Sfer D, Luccioni B. Numerical modeling of reinforced concrete beams repaired and strengthened with SFRC. Eng Struct 2015;86:168-81. 
[61] Isla F, Luccioni B, Ruano G, Torrijos MC, Morea F, Giaccio G, et al. Mechanical response of fiber reinforced concrete overlays over asphalt concrete substrate: Experimental results and numerical simulation. Constr Build Mater 2015;93: 1022-33.

[62] Máca P, Sovják R, Vavřiník T. Experimental investigation of mechanical properties of UHPFRC. Procedia Eng 2013;65:14-9.

[63] Yu R, Spiesz P, Brouwers HJH. Development of Ultra-High Performance Fibre Reinforced Concrete (UHPFRC): towards an efficient utilization of binders and fibres. Constr Build Mater 2015;79:273-82.

[64] Abu-Lebdeh T, Hamoush S, Heard W, Zornig B. Effect of matrix strength on pullout behavior of steel fiber reinforced very-high strength concrete composites. Constr Build Mater 2011;25:39-46.

[65] Gokoz UN, Naaman A. Effect of the strain-rate on the pull-out behavior of fibres in mortar. Int J Cement Compos 1981;3(3):187-202.

[66] Banthia N, Trottier JF. Deformed steel fiber-cementitious matrix bond under impact. Cement Concrete Res 1991;21:158-68.
[67] Bindiganavile V, Banthia N. Impact response of the fiber-matrix bond in concrete. Can. J Civil Eng 2005;32:924-33.

[68] Kim D, El-Tawil S, Naaman A. Loading rate effect on pullout behavior of deformed steel fibers. ACI Mater J 2008;105:576-84.

[69] Abu-Lebdeh T, Hamoush S, Zornig B. Rate effect on pullout behavior of steel fibers embedded in very-high strength concrete. Am J Eng Appl Sci 2010;3(2): 454-63.

[70] Xu M, Hallinan B, Wille K. Effect of loading rates on pullout behavior of high strength steel fibers embedded in ultra-high performance concrete. Cem. Concr. Compos 2016;70:98-109.

[71] Tai Y, El-Tawil S, Chung T. Performance of deformed steel fibers embedded in ultra-high performance concrete subjected to various pullout rates. Cem Concr Research 2016;89:1-13.

[72] Wang Z-L, Liu Y-S, Shen RF. Stress-strain relationship of steel fiber-reinforced concrete under dynamic compression. Constr Build Mater 2008;22:811-9. 